Article

\title{
Influence of the Chitosan and Rosemary Extract on Fungal Biodegradation of Some Plasticized PLA-Based Materials
}

\author{
Elena Stoleru ${ }^{1,2} \mathbb{C}$, Cornelia Vasile ${ }^{1, *} \mathbb{C}$, Lăcramioara Oprică ${ }^{3, *}$ and Onur Yilmaz ${ }^{4}(\mathbb{C}$ \\ 1 Physical Chemistry of Polymers Department, "Petru Poni" Institute of Macromolecular Chemistry, 41A, \\ Grigore Ghica Voda Alley, 700487 Iasi, Romania; elena.paslaru@icmpp.ro \\ 2 Faculty of Chemistry, "Alexandru Ioan Cuza" University of Iasi, 11 Carol I Blvd, 700506 Iasi, Romania \\ 3 Biology Faculty, “Alexandru Ioan Cuza” University of Iasi, 11 Carol I Blvd, 700506 Iasi, Romania \\ 4 Leather Engineering Department, Faculty of Engineering, Ege University, 35100 Bornova/Izmir, Turkey; \\ onuryilma@gmail.com \\ * Correspondence: cvasile@icmpp.ro (C.V.); iasilacra@yahoo.com (L.O.)
}

Received: 1 February 2020; Accepted: 15 February 2020; Published: 18 February 2020

\begin{abstract}
The fungal degradation of the complex polymeric systems based on poly(lactic acid) (PLA) and natural bioactive compounds (chitosan and powdered rosemary alcoholic extract) was studied. Two fungal strains, Chaetomium globosum and Phanerochaete chrysosporium were tested. Both fungi characteristics and changes in morphology, structure and thermal properties were monitored. Biochemical parameters as superoxide dismutase, catalase, soluble protein and malondialdehyde have been determined at different time periods of fungal degradation. The fungi extracellular enzyme activities are slightly decreased in the case of composites containing bioactive compounds. The presence of natural compounds in the PLA-based polymeric system determines an acceleration of fungal degradation and probably the chemical hydrolysis, which further helps the attachment of fungi on the surface of polymeric samples. Significant decreases in average molecular mass of the polymeric samples were observed by fungi action; accompanied by structural changes, increase in crystallinity and decrease of thermal properties and the loss of the physical integrity and finally to degradation and integration of fungal degradation products into environmental medium. It was found that both fungi tested are efficient for PLA-based materials degradation, the most active from them being Chaetomium globosum fungus.
\end{abstract}

Keywords: PLA; biodegradation; biochemical parameters; thermal behavior; bioactive compounds

\section{Introduction}

The lack of degradability and xenobiotic nature of the synthetic polymeric materials led to high levels of environmental pollution and health hazards. Recalcitrant nature of plastic is a matter of huge environmental concern, and hence new challenges are related to plastic degradation. With the increasing demand for plastics and rising pressure for their safe disposal, biodegradable plastics and plastic biodegradation gained a lot of attention in the last years. Plastics biodegradation is one of the best possible ways to treat these recalcitrant materials in an environment-friendly manner. The best possible routes of biodegradation and their associated social and environmental impacts must be selected [1]. The application of biopolymers is limited to short shelf-life products, but they show a huge potential to govern the packaging sector in the future [2].

The environmental degradation process and its duration and mechanism strongly depend on the environmental conditions including heat, humidity, $\mathrm{pH}$, oxygen, microbes and so on. High-temperature environments with a rich microorganisms presence facilitate degradation. Poly(lactic acid) (PLA) 
biodegradation is a very controversial problem because it requires temperature around $60^{\circ} \mathrm{C}$ (PLA glass transition temperature) which is not reached in normal soil conditions. In a regular room environment, PLA will resist for many years. However, PLA biodegrades because its origins are natural, is a bio-based polymer, the monomers being derived from renewable resources [3] and microorganisms can feed on it to turn it into compost $[4,5]$. Humidity, $60{ }^{\circ} \mathrm{C}$ temperature and microorganisms are required for PLA biodegradation. Occasionally such conditions are found in garden soil. In good conditions, PLA will show signs of biodegradation in 6 months [6]. Enzymes which hydrolyze PLA are not available in the environment except on very rare occasions. Proteinase K catalyzes the hydrolytic degradation of PLA but it is not commonly present in natural environments $[7,8]$.

The knowledge of the biodegradation behavior of polymers is crucial for treating plastic wastes and the serious energy crisis. The analysis of biochemical processes involved in PLA biodegradation is a key factor for exploring the high efficient methods of PLA biodegradation. PLA degradation occurs mainly through scission of ester bonds into carboxylic acid and alcohol. In addition, polymer degradation is induced by a range of factors in nature, such as oxidation, photodegradation, thermolysis, hydrolysis, biodegradation or enzymolysis $[9,10]$. During microbial degradation, PLA-degrading microorganisms first excrete extracellular depolymerase of PLA simulated by peptides and proteins [11]. The depolymerase attack intramolecular ester links of PLA, which result in production of oligomers, dimers and monomers. Afterwards the low molecular weight compounds enter in microbial membranes and decompose into carbon dioxide, water or methane by intercellular enzymes [12,13].

Therefore, the researches on pure isolation of PLA-degrading microorganisms have been raised in recent years. Currently, multiple types of microbes that are able to degrade PLA have been isolated from soil or water. They mostly are actinomycetes (Amycolatopsis, Saccharothrix, Lentzea, Kibdelosporangium, Streptoalloteichus, Pseudonocardiaceae) which accelerate PLA biodegradation in the natural soil microcosms [14,15], bacteria (Bacillus, Pseudomonas, Stenotrophomonas, etc.) and various fungi [10]. Several efficient methods were developed to accelerate degradation of commercial polylactic acid as: UV-C treatment of PLA beverage cup which reduced the molecular weight of PLA and also of the polyethylene dumped in the environment because of the presence of the Bacillus subtilis [16] which produces surface active compounds (e.g., Biosurfactants). Moreover, the burial in soil amended with various sources of microbial consortium, including cow-manure compost, green yard-waste compost, and wastewater sludges from dairy, rice vermicelli and coconut milk factories, dairy wastewater sludge accelerated complete PLA biodegradation after 15 days. A combined use of dairy sludge and Pseudomonas geniculata-WS3 is recommended for accelerating PLA degradation [17].

A few studies reported in the scientific literature deal with the fungal degradation of PLA. There are 14 filamentous fungal strains (Fusarium moniliforme and Penicillium roqueforti) able to assimilate $\mathrm{D}, \mathrm{L}$-lactic acid in liquid cultures. Moreover, fungal degradation of PLA had also been studied by using Tritirachium album (ATCC 22563) in a liquid culture [18]. It shows that most of PLA film is degraded after 14 days of cultivation by the addition of gelatin. Many studies mainly focused on the degradation of PLA by the pure cultures of fungi. However, some researchers have explored the fungal degradation of PLA in soil and compost $[19,20]$.

Recent scientific studies on the microbial degradation of natural and synthetic molecules show the potential of fungal application on cleaning technologies. It was showed by Vivi et al. [21] that from all utilized fungi, Chaetomium globosum (ATCC 16021) was a pioneer in the colonization and attack of polycaprolactone (PCL) resulting in significant mass losses. C. globosum is a saprophytic basidiomycete fungus with high capability on degrading plant materials having cellulolytic enzyme systems [22]. Chaetomium globosum is a well-known mesophilic member of the mold family Chaetomiaceae. This saprophytic fungus primarily resides on plants, soil, straw and dung [23]. The basidiomycete Phanerochaete chrysosporium is a model of ligninolytic fungus which has been studied for a long time [24]. The production of reactive oxygen species (ROS) by this fungus occurs in physiological conditions, as during the wood degradation. In our previous paper, Phanerochaete chrysosporium white rot fungus was tested for its ability to biodegrade poly(lactic acid)-based materials gamma irradiated or nitrogen 
plasma activated and chitosan-surface grafted [25]. The biodegradation of the PLA-based systems by Trichoderma viride fungus, in liquid medium and controlled laboratory conditions was also studied [26]. In both cases the accelerated fungal degradation of PLA based materials was found accompanied by average molecular weight decrease, structural and morphological changes and deterioration of the properties.

In order to gain valuable insights into the biodegradation of complex polymeric systems, the present paper aimed to develop a comparative study of the action of C. globosum and Phanerochaete chrysosporium fungi on the degradation of PLA-based complex materials containing $20 \mathrm{wt} \%$ polyethylene glycol (PEG) as plasticizer, 3-6 wt\% chitosan (CS) and 0.5 weight percent (wt\%) rosemary extract (R). It is expected that the bioactive compounds CS and R to influence the fungal degradation, as they exhibit antimicrobial, antioxidant activities and show a high potential application for food preservation and for therapeutic beneficial use, because they "contain active ingredients parts of plants, or other plant materials, or combinations" $[27,28]$.

The biodegradation was evaluated from two points of view: following the influence of the polymeric materials on biochemical enzymes specific for fungal metabolism and also by changes in physical-chemical properties of the bio-based polymeric materials as changes in average molecular weight, morphology, structure and thermal behavior.

\section{Materials and Methods}

\subsection{Materials}

PLA-based materials subjected to biodegradation under the action of Chaetomium globosum (CG) and Phanerochaete chrysosporium (PC) fungi were PLA and polyethylene glycol (PEG)-plasticized PLA as reference samples, and biocomposites containing $0.5 \mathrm{wt} \%$ powdered rosemary ethanolic extract (R), $3 \mathrm{wt} \%$ and $6 \mathrm{wt} \%$ chitosan (CS) and both additives-Table 1. The natural bioactives as chitosan and rosemary ethanolic extract were selected to offer multifunctionality, as antimicrobial, antioxidant and biocompatibility to PLA materials, with potential applications both in food packaging and biomaterials, as it was demonstrated in our previous paper [29]. Their role was described in our previous papers $[26,30]$.

Table 1. Poly(lactic acid) (PLA)-based samples that were exposed to fungal biodegradation.

\begin{tabular}{|c|c|c|}
\hline \multicolumn{3}{|c|}{ Samples Description and Codes } \\
\hline \multirow{2}{*}{ Before Biodegradation } & \multicolumn{2}{|c|}{ After Biodegradation ( 7 or 14 days) } \\
\hline & Chaetomium globosum (CG) & Phanerochaete chrysosporium (PC) \\
\hline Native poly(lactic acid) (PLA) & PLA/7d/CG or PLA/14d/CG & PLA/7d/PC or PLA/14d/PC \\
\hline $\begin{array}{l}\text { PLA plasticized with polyethylene glycol } \\
\text { (PLA/PEG) }\end{array}$ & PLA/PEG/7d/CG or PLA/PEG/14d/CG & PLA/PEG/7d/PC or PLA/PEG/14d/PC \\
\hline $\begin{array}{l}\text { PLA containing powdered rosemary } \\
\text { ethanolic extract (R) } 0.5 \% \text { (PLA/R) }\end{array}$ & PLA/R/7d/CG or PLA/R/14d/CG & PLA/R/7d/PC or PLA/R/14d/PC \\
\hline $\begin{array}{l}\text { PLA plasticized with PEG containing } \\
\text { powdered rosemary ethanolic extract } \\
\text { (PLA/PEG/R) }\end{array}$ & $\begin{array}{l}\text { PLA/PEG/R/7d/CG or } \\
\text { PLA/PEG/R/14d/CG }\end{array}$ & $\begin{array}{l}\text { PLA/PEG/R/7d/PC or } \\
\text { PLA/PEG/R/14d/PC }\end{array}$ \\
\hline $\begin{array}{l}\text { PLA/PEG containing } 3 \mathrm{wt} \% \text { chitosan } \\
\text { (PLA/PEG/3CS) }\end{array}$ & $\begin{array}{l}\text { PLA/PEG/3CS/7d/CG or } \\
\text { PLA/PEG/3CS/14d/CG }\end{array}$ & $\begin{array}{l}\text { PLA/PEG/3CS/7d/PC or } \\
\text { PLA/PEG/3CS/14d/PC }\end{array}$ \\
\hline $\begin{array}{l}\text { PLA/PEG containing } 6 \mathrm{wt} \% \text { chitosan } \\
\text { (PLA/PEG/6CS) }\end{array}$ & $\begin{array}{l}\text { PLA/PEG/6CS/7d/CG or } \\
\text { PLA/PEG/6CS/14d/CG }\end{array}$ & $\begin{array}{l}\text { PLA/PEG/6CS/7d/PC or } \\
\text { PLA/PEG/6CS/14d/PC }\end{array}$ \\
\hline $\begin{array}{c}\text { PLA/PEG/R containing } 3 w t \% \text { chitosan and } \\
\text { powdered rosemary ethanolic extract } \\
(\text { PLA/PEG/3CS/R) }\end{array}$ & $\begin{array}{l}\text { PLA/PEG/3CS/R/7d/CG or } \\
\text { PLA/PEG/3CS/R/14d/CG }\end{array}$ & $\begin{array}{l}\text { PLA/PEG/3CS/R/7d/PC or } \\
\text { PLA/PEG/3CS/R/14d/PC }\end{array}$ \\
\hline $\begin{array}{c}\text { PLA/PEG/R containing } 6 \mathrm{wt} \% \text { chitosan } \\
\text { powdered rosemary ethanolic extract } \\
\text { (PLA/PEG/6CS/R) }\end{array}$ & $\begin{array}{l}\text { PLA/PEG/6/CS/R/7d/CG or } \\
\text { PLA/PEG/6CS/R/14d/CG }\end{array}$ & $\begin{array}{l}\text { PLA/PEG/6/CS/R/7d/PC or } \\
\text { PLA/PEG/6CS/R/14d/PC }\end{array}$ \\
\hline
\end{tabular}




\subsection{Fungal Material}

Detailed experimental conditions have been described in a previous paper [25]. Chaetomium globosum and Phanerochaete chrysosporium fungi purchased from the Institut Scientifique de Sante Publique, Belgium, preserved in the laboratory conditions have been used in this study. Peptone, yeast extract, malt extract, agar-agar and Coomassie Brilliant Blue G250 (Fluka Switzerland), nitro blue tetrazolium, riboflavin, o-dianisidine and hydrogen peroxide (Sigma-Aldrich, Germany), sulfuric acid, perchloric acid, 2-thiobarbituric acid, bovine serum albumin and other chemicals (Merck, Germany) were of analytical grade ones. High purity double distilled water was employed for preparation of solutions.

\subsection{Fungal Strains and Culture Conditions}

C. globosum was grown on agarized Haynes medium (yeast extract $4 \mathrm{~g} / \mathrm{L}$, malt extract $10 \mathrm{~g} / \mathrm{L}$, glucose $4 \mathrm{~g} / \mathrm{L}$, agar $15 \mathrm{~g} / \mathrm{L}$ in distilled water) [31], while $P$. chrysosporium fungus was cultivated with solid Sabouraud agar growth medium (peptone $10 \mathrm{~g} / \mathrm{L}$, glucose $35 \mathrm{~g} / \mathrm{L}$, agar $20 \mathrm{~g} / \mathrm{L}$ in distilled water), keeping them for 7 days at $28 \pm 0.1{ }^{\circ} \mathrm{C}$ and stored at $4{ }^{\circ} \mathrm{C}$. The discs of $0.8 \mathrm{~cm}$ in diameter from both fungi cultures were inoculated into $100 \mathrm{ml}$ Haynes liquid or Sabouraud liquid media with 7 days old cultures of fungi, respectively using Erlenmeyer flasks. The biodegradation test was performed in controlled laboratory conditions for 14 days using the polymeric samples cut into $20 \times 20 \mathrm{~mm}$ specimens, thickness $3 \pm 0.1 \mathrm{~mm}$. Samples were incubated at $28 \pm 0.1^{\circ} \mathrm{C}$ in the Incucell room and grown to stationary phase. The both controls were represented by the mycelium grown in the absence of polymeric samples.

\subsection{Investigation Methods}

\subsubsection{Scanning Electron Microscopy (SEM)}

The surface morphology of the films before and after fungal biodegradation was examined by scanning electron microscopy (SEM), using a QUANTA 200 scanning electronic microscope (FEI Company, Hillsboro, OR, USA), at an accelerating voltage of 10 and $20 \mathrm{kV}$. The surfaces of PLA-based samples were examined as such (without metal coating) and SEM micrographs being recorded at different magnifications (given on the images). This technique allows to directly performing morphological and surface characterization as well as their three-dimensional shape of morphological features, the presence of aggregates, voids, etc. SEM is a useful tool for evaluating the changes that occur in the microstructure of polymers during degradation/ageing.

\subsubsection{Biochemical Assays}

To C. globosum or P. chrysosporium mycelium $(0.5 \mathrm{~g})$ were added $2 \mathrm{~mL}$ of $0.1 \mathrm{M}$ phosphate buffer solution (pH 7.5) and were subsequently centrifuged at $11,300 \mathrm{rpm}$, at $4{ }^{\circ} \mathrm{C}$. The superoxide dismutase, catalase, soluble protein and malondialdehyde, as biochemical parameters were determined on fungus mycelium after different inoculation period as 7 and 14 days. Superoxide dismutase (SOD) activity was obtained from light absorbance at $560 \mathrm{~nm}$ wavelength by adapted colorimetric Winterbourn method, while the catalase (CAT) activity through the method described by Sinha (1972) [32]. Lipid peroxidation was determined as malondialdehyde (MDA) content using thiobarbituric acid (TBA) according to the procedures described by Hodges et al. [33]. All results were expressed relatively to protein content (according to Bradford, 1976 assay) [34] and graphically drawn as average values and standard deviations resulted from five repeated measurements.

\subsubsection{ATR-FTIR Spectroscopy}

To determine the structural changes occurred during fungal degradation of the PLA-based biocomposites, the attenuated total reflection-Fourier transform infrared spectroscopy (ATR-FTIR) 
technique was used. The background and samples spectra were recorded with a Bruker VERTEX 70 spectrometer (Bruker, USA) in the 600 to $4000 \mathrm{~cm}^{-1}$ wavenumber range, at a $4 \mathrm{~cm}^{-1}$ resolution by performing 136 scans. The ATR module is equipped with a $45^{\circ} \mathrm{ZnSe}$ crystal (penetration thickness is around $100 \mu \mathrm{m}$ ). For each sample, the evaluations were made on the average spectrum obtained from three recordings. Spectrum processing was performed using OPUS and ORIGIN programs.

\subsubsection{Gel Permeation Chromatography (GPC)}

Average molecular weights of the samples before and after incubation with fungi were determined by Gel Permeation Chromatography instrument WGE SEC-3010 multi-detection system (Brookhaven, GA, USA), consisting of a pump, two PLgel columns (PLgel is a highly cross linked, porous polystyrene/divinylbenzene matrix), and dual detector RI/VI (Refractometer/Viscometer) WGE SEC-3010. The working solutions were prepared in chloroform $\left(\mathrm{CHCl}_{3}\right)$ and the experiments were achieved using a flow rate of $1.0 \mathrm{~mL} / \mathrm{min}$ at $30^{\circ} \mathrm{C}$ temperature. The RI/VI detector was calibrated with PS standards (580-1350000 DA) having narrow molecular weight distribution. Fragments of the samples were dissolved in HPLC grade chloroform $\left(\mathrm{CHCl}_{3}\right)\left(0.02 \mathrm{~g} / \mathrm{mL} \mathrm{CHCl}_{3}\right)$ and stirred at $25^{\circ} \mathrm{C}$, for $1 \mathrm{~h}$, using a heater-stirrer. Diluted solutions were filtered using a 0.2 Teflon filter to extract insoluble fraction, before injecting the solute through the PLgel columns. Weight average molecular mass (Mw), number average molecular weight $(\mathrm{Mn})$, as well as the polydispersity index (Mw/Mn) and viscosity were determined, using the PARSEC Chromatography software. The mean of at least two injections are given.

\subsubsection{Differential Scanning Calorimetry (DSC)}

For Differential Scanning Calorimetry a Shimadzu 60 Plus instrument (Kyoto, Japan) was used to examine the thermal behavior of PLA-based samples. The samples were sealed in aluminum pans. Differential scanning calorimetry (DSC) analysis was conducted under nitrogen flow $(20 \mathrm{~mL} / \mathrm{min})$ within a temperature range of 20 and $250{ }^{\circ} \mathrm{C}$ with a heating rate of $10{ }^{\circ} \mathrm{C} / \mathrm{min}$. Calibration was performed using an indium standard $\left(T_{\mathrm{m}}=156.6{ }^{\circ} \mathrm{C} ; \Delta H_{\mathrm{m}}=28.45 \mathrm{~J} / \mathrm{g}\right)$. The degree of crystallinity $\left(X_{\mathrm{c}}\right)$ of the PLA and its composites was calculated by dividing the melting enthalpy of the sample by $\Delta H_{\mathrm{m}}=93.7 \mathrm{~J} / \mathrm{g}$, which is equilibrium enthalpy of a PLA sample with $100 \%$ crystallinity (PLA $100 \%$ ). An overall accuracy of $\pm 0.5^{\circ} \mathrm{C}$ in temperature and $\pm 1 \%$ in enthalpy was estimated [35].

\subsubsection{Thermogravimetry (TG)}

Thermogravimetry was performed by using a Perkin Elmer TGA 8000 (Shelton, CT, USA) device to evaluate the thermal degradation process of the samples. The temperature program was set from 30 to $700{ }^{\circ} \mathrm{C}$ with a heating rate of $10^{\circ} \mathrm{C} / \mathrm{min}$ under $\mathrm{N}_{2}$ flow $(20 \mathrm{~mL} / \mathrm{min})$.

\section{Results and Discussion}

\subsection{Visual Inspection and Scanning Electron Microscopy (SEM)}

The PLA-composite samples were characterized before and after each exposure period ( 7 and 14 days) in fungal media.

The presence of biodegradable polysaccharide, chitosan, into PLA-based composites hastened the disintegration rate; the composite samples exposed to liquid incubation medium were completely disintegrated after 7 days. Is noticed that the presence of PEG plasticizer in PLA matrix leads to an accelerated degradation of the polyester, the visual inspection highlighting the changing color from pale yellow (initial PLA/PEG) to white and a marked increase of brittleness (after 14 days the samples become difficult to handle)-Figure 1. It is also possible that PEG is lost from samples during fungal test. 



Figure 1. Visual appearance of PLA/polyethylene glycol (PEG) sample before and after 7 days exposure to Chaetomium globosum (CG) and Phanerochaete chrysosporium (PC) fungi.

The occurred changes in the optical properties of the samples may be due to the modification of their crystallinity and/or water absorption and to biodegradation process. Based on visual examination it can be noted that the samples exposed to Chaetomium globosum fungus undergoes a more pronounced change of the initial features.

The SEM photomicrographs (Figure 2) show that the surface of non-degraded PLA material is smooth, without cracks and holes, while after fungal exposure the surfaces of PLA and PLA/R become rougher, being highlighted surface defects. Is noticed also that the samples were covered with hyphae and characteristic spores, meaning that the used fungi expanded their colonies and cover the entire samples surface, this aspect being more pronounced in the case of exposure to Chaetomium globosum fungus. The presence of the rosemary powder into PLA matrix composition, besides the adhesion of the fungi to the surface, causes cracks into the sample.

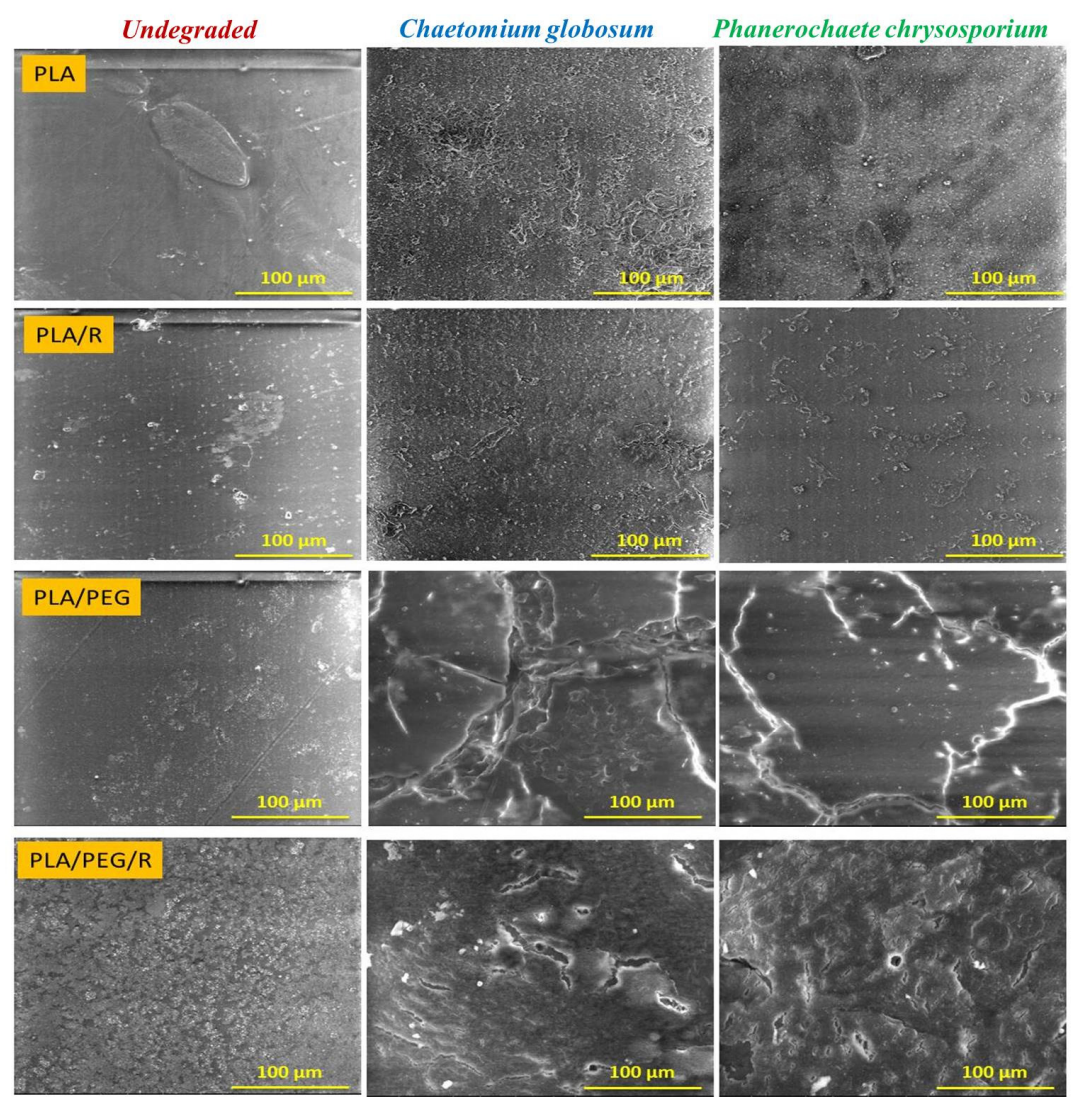

Figure 2. SEM micrographs (magnification of $1000 \times$, scale bar-100 $\mu \mathrm{m}$ ) of PLA-based samples after 14 days in Chaetomium globosum and Phanerochaete chrysosporium fungi comparatively with undegraded ones. 
Dense network of fractures was particularly visible for the samples containing PEG; this may be due to the hydrophilic nature of the plasticizer, which makes the samples more accessible for fungal attack. PLA/PEG and PLA/PEG/R samples after 14 days incubation with Chaetomium globosum and Phanerochaete chrysosporium fungi were covered by cracks of varying diameters which eventually created holes. Larger cracks are observed when the samples were incubated with Chaetomium globosum, resulting in loss of integrity of the sample. These findings may suggest that PLA-based samples served as the source of carbon and energy for the studied fungi. As revealed by SEM images in Figure 3, peeling and exfoliation appeared in sample containing PEG and rosemary powder, the destructive process of biodegradation being most prominent in this case. The SEM micrographs highlights that the fungal degradation clearly occurs from the surface.
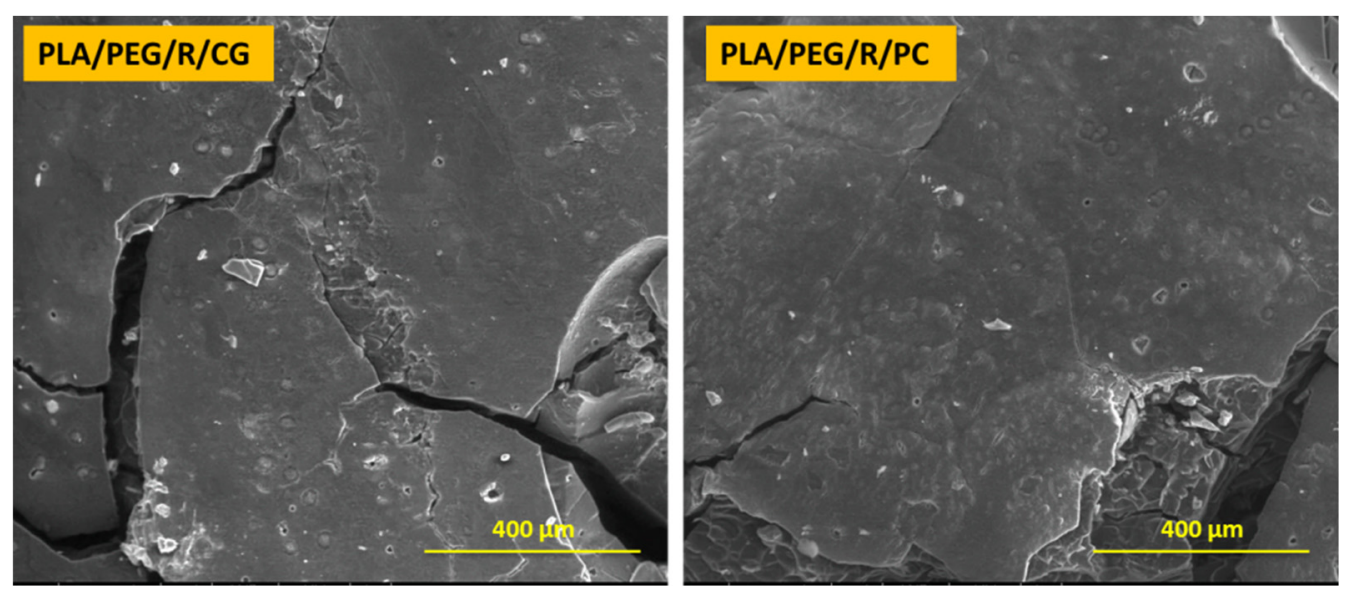

Figure 3. SEM micrographs (magnification of $250 \times$, scale bar-400 $\mu \mathrm{m}$ ) of PLA/PEG/R sample after 14 days incubation with Chaetomium globosum (CG) and Phanerochaete chrysosporium (PC) fungi.

\subsection{Weight Loss Measurements}

Weight losses are widely applied in the biodegradation tests, although no precise proof of evaluation can be obtained [36]. In the present study, the weight loss was determined after 7 and 14 days of fungus incubation, by carefully removing the sample from the medium and washing it with distilled water. The samples were subsequently dried at $30^{\circ} \mathrm{C}$, until constant weight was obtained. The weight losses (Equation (1)) were calculated as difference between the mass of the sample after biodegradation $\left(m_{d}\right)$ and before $\left(m_{0}\right)$ and were expressed as percentages.

$$
\text { Weight loss }(\%)=\frac{m_{0}-m_{d}}{m_{0}} \times 100
$$

Measurements of mass loss can be problematic due to moisture absorption or difficult recovery of disintegrated material. In Table 2 is shown the percentage weight loss of the samples degraded by Chaetomium globosum and Phanerochaete chrysosporium, the values represent an average of three experiments.

It is known that native PLA has a slow rate of disintegration and the microorganisms that degrade PLA are rarely found in nature [37]. Among the tested samples, the native PLA showed the lowest degradation rate, only $22 \%$ weight loss was found after 14 days of exposure to Chaetomium globosum. The PLA-based composites samples exhibited relatively high rates of weight loss, $43 \%$ within 14 days. In the presence of the rosemary extract alone, the weight loss is smaller mainly after 7 days fungal degradation because of its high content in phenolic compounds with antioxidant activity [38]. The PEG plasticized PLA-based composites and containing CS and $\mathrm{R}$ were the most rapidly degraded samples, which exhibited a $100 \%$ weight loss (more exactly the recovery of disintegrated material was not possible or they are totally integrated in fungal degradation media). The sterile controls (polyethylene films) showed no weight loss in the tested period. The addition of hydrophilic plasticizer 
(PEG) caused an increase in weight loss of 43-57\%. The rate of weight loss differed between the studied fungi cultures, the samples inoculated with Chaetomium globosum shows average percentage of weight loss higher than the ones exposed to Phanerochaete chrysosporium. Similar results were reported also by Geweely and Ouf [39] testing these two fungi on starch based polymers.

Table 2. The percent of weight loss of PLA-based samples subjected to fungal cultures.

\begin{tabular}{ccccc}
\hline \multirow{2}{*}{ Sample } & \multicolumn{4}{c}{ Weight Loss (\%) } \\
\cline { 2 - 5 } & \multicolumn{2}{c}{ Chaetomium } & globosum & Phanerochaete chrysosporium \\
\cline { 2 - 5 } & $\mathbf{7}$ days & 14 days & $\mathbf{7}$ days & 14 days \\
\hline PLA & 18 & 22 & 9 & 18 \\
PLA/PEG & 43 & 57 & 42 & 49 \\
PLA/R & 31 & 42 & 25 & 33 \\
PLA/PEG/R & 42 & 49 & 40 & 47 \\
PLA/PEG/3CS & 100 & 100 & 100 & 100 \\
PLA/PEG/6CS & 100 & 100 & 100 & 100 \\
PLA/PEG/3CS/R & 100 & 100 & 100 & 100 \\
PLA/PEG/6CS/R & 100 & 100 & 100 & 100 \\
\hline
\end{tabular}

\subsection{Biochemical Results}

Both the characteristics of the fungi and their activities on polymer degradation depend on enzymes action, therefore, biochemical studies are necessary to elucidate the fungal bioactivity which gives information about their role in polymer biodegradation. Cells continuously produce free radicals and reactive oxygen species (ROS) as part of their metabolic processes, but in case of their overproduction the oxidative stress occurs. Current knowledge has shown that ROS play a key role as an agent in normal cell signal transduction and cell cycling [40].

Hancock et al. (2001) [41] demonstrated in their work that ROS have a role in cell signaling, including apoptosis; gene expression; and the activation of cell signaling cascades. As a result of this, several barricade mechanisms have evolved to meet this need and provide a balance between production and removal of ROS. Cells have categories of fortifying mechanisms to ameliorate the harmful effects of ROS. The ROS defense mechanism consists of the antioxidant machinery which helps to mitigate the above-mentioned oxidative stress-induced damages. The damaging effects of ROS are ameliorated by different antioxidative defense systems and the antioxidant machinery has two arms with the enzymatic components and non-enzymatic antioxidants [42]. Antioxidants are compounds that inhibit oxidation process. By their radical scavenging activity, they assure the protection of the materials such as biomolecules $[43,44]$.

To evaluate the ROS-scavenging action, in the present study, the activities of two key antioxidant enzymes, superoxide dismutase and catalase, were monitored as being of importance in oxidative stress defense in P. chrysosporium and C. globosum fungi (Figures 4 and 5a,b). The enzymes work together to detoxify the ROS generated by biotic and abiotic stress [45]. 


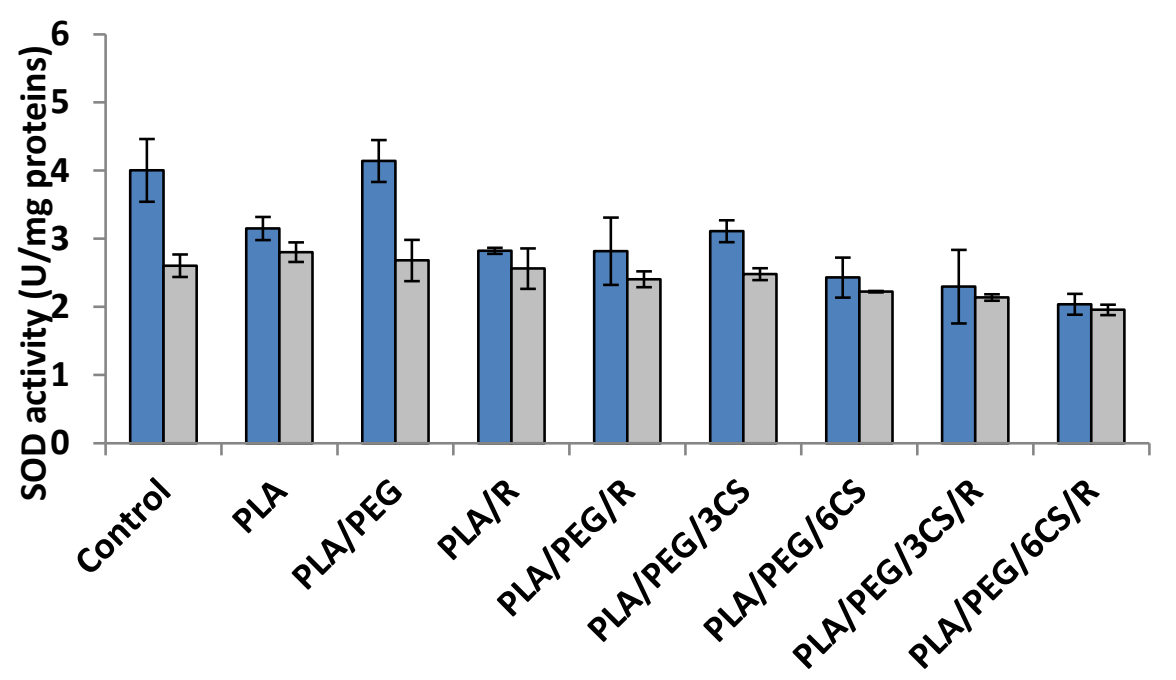

(a)

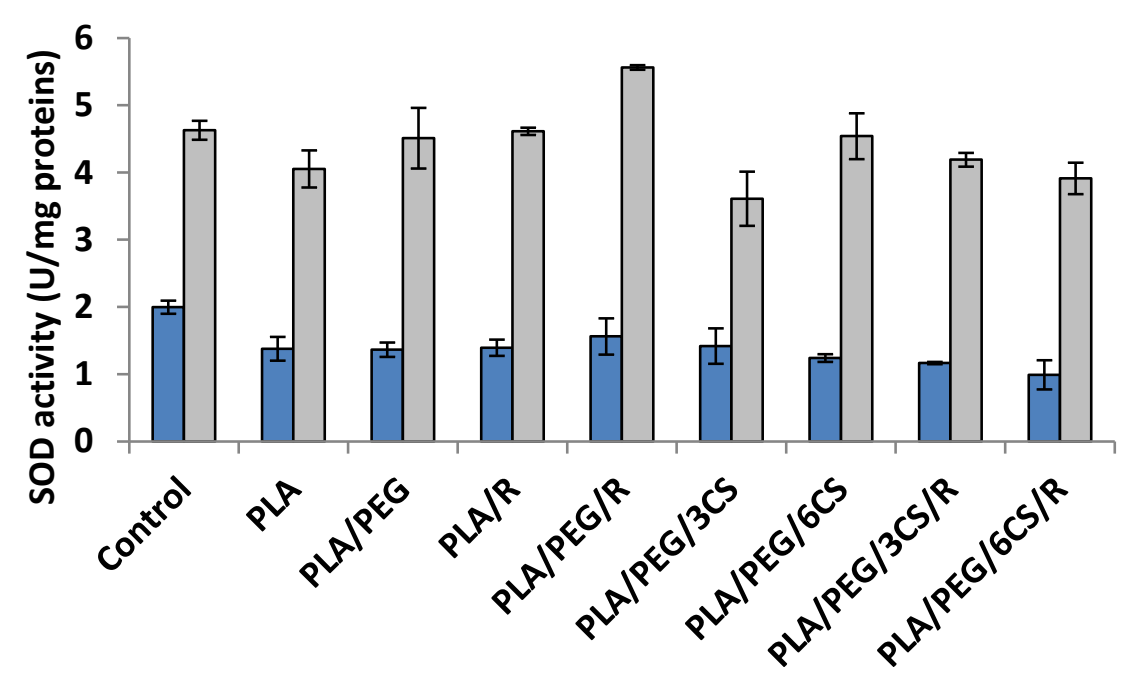

(b)

Figure 4. Superoxid dismutase (SOD) activity in P. chrysosporium (dark blue columns) and C. globosum (grey columns) after 7 days (a) and 14 days (b) of incubation in the presence of PLA-based samples.

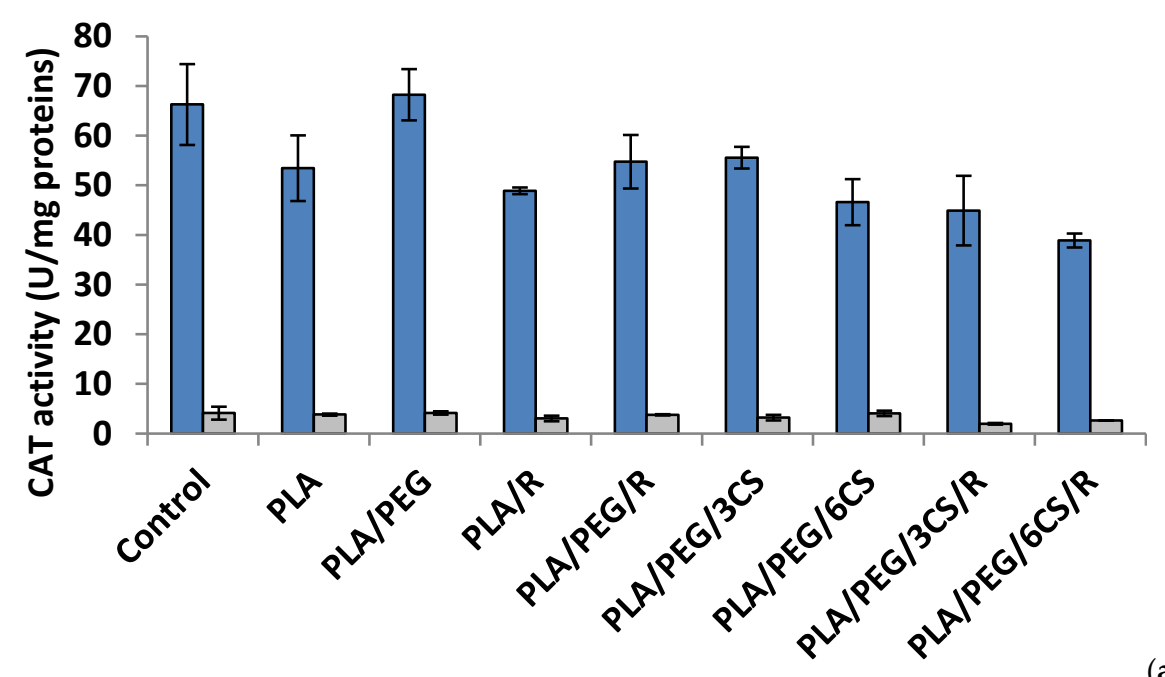

Figure 5. Cont. 


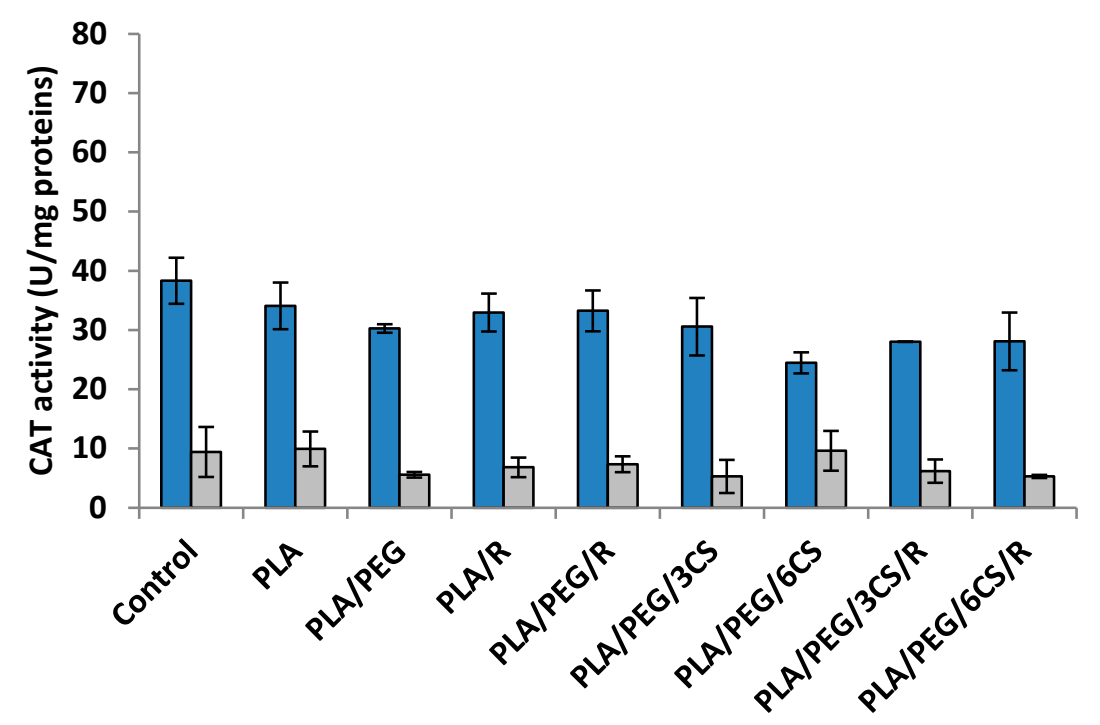

(b)

Figure 5. Catalase (CAT) activity in P. chrysosporium (dark blue columns) and C. globosum (grey columns) after 7 days (a) and 14 days (b) of incubation in the presence of PLA-based samples.

Another parameter of oxidative damage evidenced in the mycelium of both fungi was measured as malondialdehyde content (MDA) (Figure 6a,b).

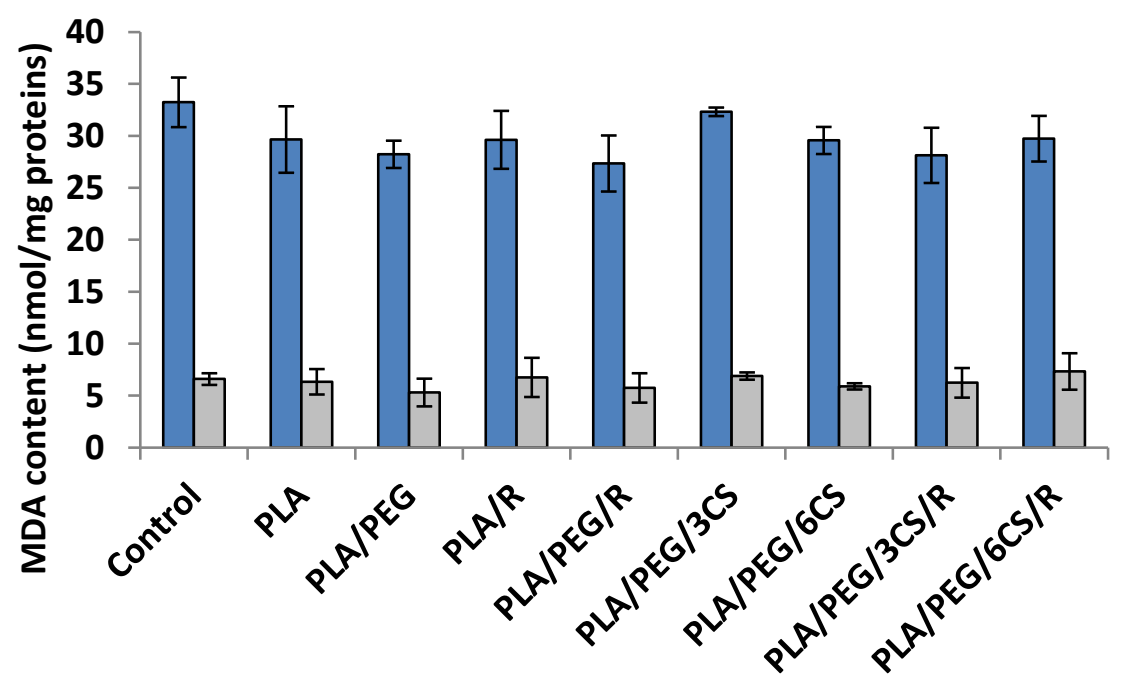

(a)

Figure 6. Cont. 


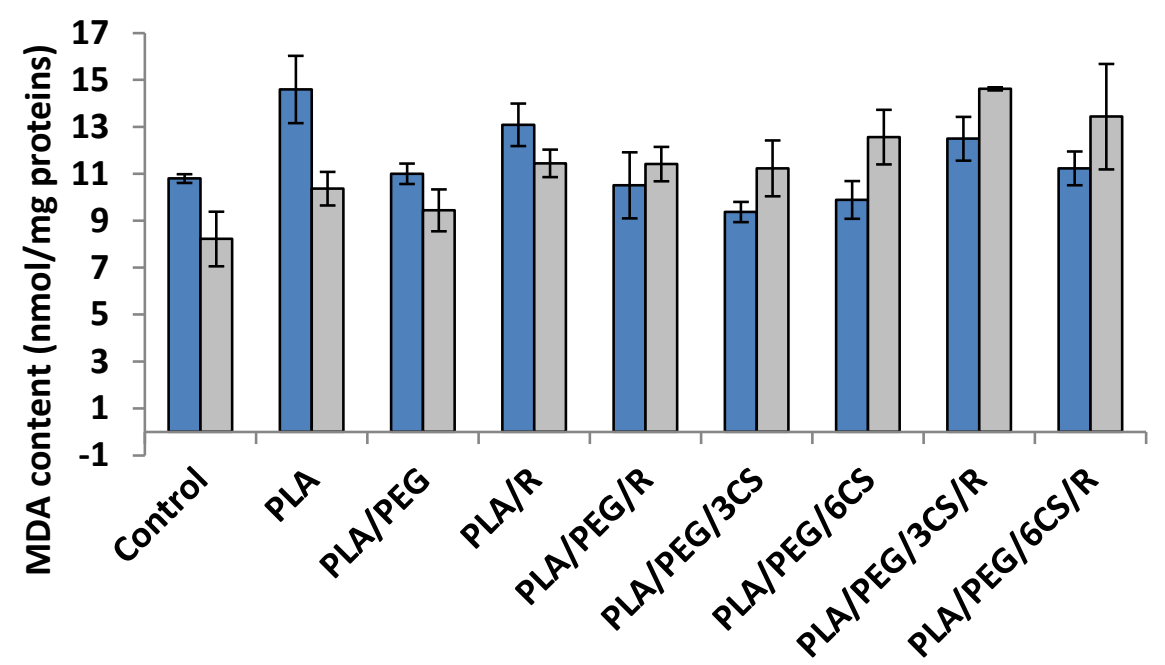

(b)

Figure 6. Malondialdehyde (MDA) content in P. chrysosporium (dark blue columns) and C. globosum (grey columns) after 7 days (a) and 14 days (b) of incubation in the presence of PLA-based samples.

Effect of the PLA-based samples on superoxide dismutase activity. Superoxide dismutase (SOD) (EC.1.15.1.1) is considered as a key enzyme in cells, a first line of defense against oxidative damage induced by various environmental factors. The SOD catalyzes the dismutation of two molecules of superoxide anion $\left(\mathrm{O}_{2}^{-}\right)$to hydrogen peroxide $\left(\mathrm{H}_{2} \mathrm{O}_{2}\right)$ and molecular oxygen $\left(\mathrm{O}_{2}\right)$, consequently rendering the potentially harmful superoxide anion less hazardous one [46]. The polymeric samples introduced in culture media of Phanerochaete chrysosporium determine at 7 days after incubation a diminution of SOD activity (Figure 4a). The sample with PLA/PEG/6CS/R caused a decrease of SOD activity with $50 \%$ reported to control. In Chaetomium globosum mycelium, SOD activity recorded a heterogeneous response; the sample with PLA/PEG/6CS/R determined the lowest enzyme activity $(24 \%)$ while PLA sample the higher activity $(7 \%)$ compared with control. At another studied time interval, 14 days after inoculation, the trend of SOD activity was the same, for both species of fungi but on a different scale values (Figure $4 \mathrm{~b}$ ). Thus, in case of $P$. chrysosporium the profile of SOD activity was similar with that recorded at 7 days after incubation with polymer samples; in addition, the sample with PLA/PEG/6CS/R was found to majorly contribute to the decrease of enzyme (50\%) comparatively with control. On the other hand, in C. globosum mycelium, SOD activity was very different, PLA/PEG/R sample determined the maximum activity (stimulation rate $20 \%$ ) while PLA/PEG/3CS samples evidenced a lowest activity $15 \%$ compared with the control.

Effect of the PLA-based samples on catalase activity. Catalase (CAT) (EC 1.11.1.6) is a common antioxidant enzyme present almost in all living tissues that utilize oxygen which catalyzes the degradation or reduction of hydrogen peroxide $\left(\mathrm{H}_{2} \mathrm{O}_{2}\right)$ to water and molecular oxygen, consequently completing the detoxification process imitated by SOD [47]. Among all antioxidative enzymes, $\mathrm{CAT}$ has one of the highest turnover rates: one molecule of CAT can convert around 6 million $\mathrm{H}_{2} \mathrm{O}_{2}$ molecules to $\mathrm{H}_{2} \mathrm{O}$ and $\mathrm{O}_{2}$ per minute, and stress conditions reduce the rate of protein turnover [48].

The data of Figure 5a indicated that at 7 days after inoculations, the majority of polymeric samples (excepting PLA/PEG) determined a decrease of CAT activity; in P. chrysosporium mycelium a more intense decrease $(41 \%)$ was recorded at PLA/PEG/6CS/R sample. The CAT activity was diminished by introducing the polymeric samples in culture media of $C$. globosum and the lowest value being registered at PLA/PEG/3CS/R sample. In the 14 day after inoculation (Figure $5 \mathrm{~b}$ ) of P. chrysosporium media, all used polymers caused a decrease of CAT activity, the lowest activity being at PLA/PEG/6CS. In $C$. globosum mycelium, the CAT activity was lower than control. However, only polymers PLA/PEG/6CS and PLA samples had CAT values comparable to those of the control.

An interesting finding is the fact that after 7 days of incubation with fungi, the presence of PEG plasticizer into PLA matrix determines an increase of enzymes activity, while after 14 days this feature is 
no longer preserved. Evaluating the extracellular enzyme activity in mycelium for both studied fungal strains, one can conclude that the presence of chitosan and rosemary powdered extract into PLA-based samples led to the consumption of the enzymes produced by the two fungi in biodegradation process of the PLA-based complex polymeric samples. The action of the C. globosum seems to be higher than that of P. chrysosporium. This is not really surprising taking into account the known property of chitosan to inhibit other enzymes activities [49]. These findings suggest that biodegradation of the complex PLA polymeric samples is based on a fungal enzymatic action but also other chemical processes may play a significant role.

Effect of the PLA-based samples on malondialdehyde concentration. Malondialdehyde (MDA) is one of the most known secondary products of lipid peroxidation, and it can be used as one of the most frequent biomarker of cell membrane injury [50].

The ROS-induced peroxidation of the lipid membranes is a reflection of stress-induced damage at the cellular level [51].

After 7 days, all polymer samples in contact with P. chysosporium media displayed a diminution of MDA content, compared to the control-Figure 6a. Thus, the low MDA content provides evidence of lower mycelium membrane damage. In contrast, the situation however changed in the case of values obtained after 14 days of experiment (Figure $6 \mathrm{~b}$ ) when all values of this biochemical parameter are much lower than those recorded after 7 day fungal degradation period up to three times smaller (about $10 \mathrm{nmol} / \mathrm{mg}$ protein in comparison with $35 \mathrm{nmol} / \mathrm{mg}$ protein) with the highest values for degradation under P. chysosporium fungus. Thereby, as light enhanced level of lipid peroxidation, as indicated by the MDA content, was observed after 14 days in P. chysosporium mycelium in response to presence of the polymeric samples. Thus, it would indicate a decreased oxidative stress as effect of polymeric samples. However, only PLA/PEG/3CS and PLA/PEG/6CS has determined the least amount of MDA measured, with $10 \%$ and $8 \%$, respectively (Figure 6 ).

The polymeric samples in contact 7 days with C. globosum suggest MDA values very close to the control. However, the higher increase (11\%) was observed in the case of PLA/PEG/6CS/R sample. Regarding the content of MDA measured after 14 days of inoculation (Figure $6 \mathrm{~b}$ ) the results showed an increase of this marker of lipids peroxidation in the mycelium of $C$. globosum, varying between $14 \%$ and $77 \%$ at PLA/PEG and PLA/PEG/3CS/R, respectively. Moreover, the polymer samples also determined at $C$. globosum mycelium an increase in MDA content, indicating the presence of oxidative stress, similar to P. chysosporium.

Based on the MDA level found for both fungi it can be specified that $C$. globosum fungus is more active against oxidative stresses induced by the biodegradation of complex PLA-based samples.

\subsection{GPC Results-Average Molecular Weight Determination}

Biodegradation efficiency achieved by the microorganisms is directly related to the key properties such as molecular weight and crystallinity of the polymers, which also changed during degradation, being important proofs for degradation progress. Enzymes engaged in polymer degradation initially are outside the cell and are referred to as exo-enzymes having a wide reactivity ranging from oxidative to hydrolytic functionality. The exo-enzymes generally degrade complex polymer structure to smaller, simple units that can take in the microbial cell to complete the process of degradation. Even, the major commercial polymers such as polyolefins, poly(vinyl chloride, poly(ethyleneterephthalate), brominated high impact polystyrene, and polyurethanes have been shown to be biodegradable in a variety of circumstances (as in presence of certain microbial species) despite a strong predisposition suggesting that many of these polymers were recalcitrant to the effects of biodegradation [52].

The average molecular weight of the PLA-based materials before and after fungal degradation was determined by GPC technique, using a refractive index detector. The representative chromatograms are given in Figure 7 and obtained data are summarized in Table 3. 



(a)

Figure 7. GPC chromatograms of (a) PLA and (b) PLA/PEG/R samples before and after 14 days exposure to Chaetomium globosum (CG) and Phanerochaete chrysosporium (PC) fungi.

For all samples, it appears a clear tendency to decrease of molecular weight after fungal degradation both for PLA and PLA/R. For PEG-plasticized samples the main peak on chromatograms is split in two with increasing proportion of fractions with low molecular weight. This can be due to loss of PEG which has a low molecular weight and also to degradation. Similar trend was found also in variation of the intrinsic viscosity.

Table 3. Average number $(\mathrm{Mn})$, weight $(\mathrm{Mw})$ and $\mathrm{Z}$ average $(\mathrm{Mz})$ molecular weight, polydispersity $(\mathrm{Mw} / \mathrm{Mn}, \mathrm{Mz} / \mathrm{Mw})$ and intrinsic viscosity [ $\eta]$ of the PLA-based samples before and after 14 days of fungal degradation.

\begin{tabular}{|c|c|c|c|c|c|c|}
\hline Sample & $\begin{array}{c}\mathrm{Mn} \times 10^{2} \\
\mathrm{~g} / \mathrm{mol}\end{array}$ & $\begin{array}{c}\mathrm{Mw} \times 10^{2} \\
\mathrm{~g} / \mathrm{mol}\end{array}$ & $\begin{array}{c}\mathrm{Mz} \times 10^{2} \\
\mathrm{~g} / \mathrm{mol}\end{array}$ & Mw/Mn & $\mathbf{M z} / \mathbf{M w}$ & {$[\eta] \mathrm{mL} / \mathrm{g} \times 10^{2}$} \\
\hline PLA & 1150 & 2170 & 3670 & 1.878 & 1.695 & 1.447 \\
\hline PLA/14d/CG & 626 & 1000 & 1540 & 1.598 & 1.539 & 0.739 \\
\hline PLA/14d/PC & 526.2 & 889.0 & 1404 & 1.690 & 1.579 & 0.688 \\
\hline \multirow{2}{*}{ PLA/PEG } & 92.2 & 110.2 & 138.2 & 1.169 & 1.254 & 0.061 \\
\hline & 38.46 & 44.28 & 49.56 & 1.151 & 1.119 & 0.131 \\
\hline \multirow{2}{*}{ PLA/PEG/14d/CG } & 87.1 & 103.2 & 123.1 & 1.183 & 1.193 & 0.06 \\
\hline & 44.18 & 47.01 & 49.99 & 1.064 & 1.063 & 0.188 \\
\hline \multirow{2}{*}{ PLA/PEG/14d/PC } & 84.4 & 88.48 & 92.94 & 1.049 & 1.050 & 0.012 \\
\hline & 39.87 & 43.79 & 31.29 & 1.098 & 1.101 & 0.619 \\
\hline PLA/R & 1060 & 1788 & 2864 & 1.687 & 1.602 & 1.293 \\
\hline PLA/R/14d/CG & 456.2 & 768.0 & 1209 & 1.683 & 1.574 & 0.635 \\
\hline PLA/R/14d/PC & 374.1 & 635.3 & 984.9 & 1.698 & 1.550 & 0.567 \\
\hline \multirow{2}{*}{ PLA/PEG/R } & 95.20 & 113.0 & 140.8 & 1.187 & 1.247 & 0.071 \\
\hline & 39.40 & 44.85 & 50.03 & 1.138 & 1.115 & 0.016 \\
\hline \multirow{2}{*}{ PLA/PEG/R/14d/CG } & 88.54 & 92.92 & 97.61 & 1.050 & 1.050 & 0.019 \\
\hline & 49.64 & 51.94 & 54.49 & 1.046 & 1.049 & 0.019 \\
\hline \multirow{2}{*}{ PLA/PEG/R/14d/PC } & 86.29 & 91.26 & 96.39 & 1.058 & 1.056 & 0.382 \\
\hline & 44.36 & 47.05 & 50.28 & 1.061 & 1.069 & 0.0058 \\
\hline
\end{tabular}

\subsection{Structural Changes-Fourier-Transform Infrared Spectroscopy (ATR-FTIR) Results}

It is well accepted [53] that the biodegradation of PLA is preceded by the chemical hydrolysis of ester bonds in the polymer, which is connected with the decrease of average molecular weight to the level accessible by the enzymatic systems of microorganisms action [38]. The FTIR spectra of PLA, PLA/R, PLA/PEG and PLA/PEG/R before and after being inoculated with Chaetomium globosum and Phanerochaete chrysosporium fungi are shown in Figure 8a,b. 

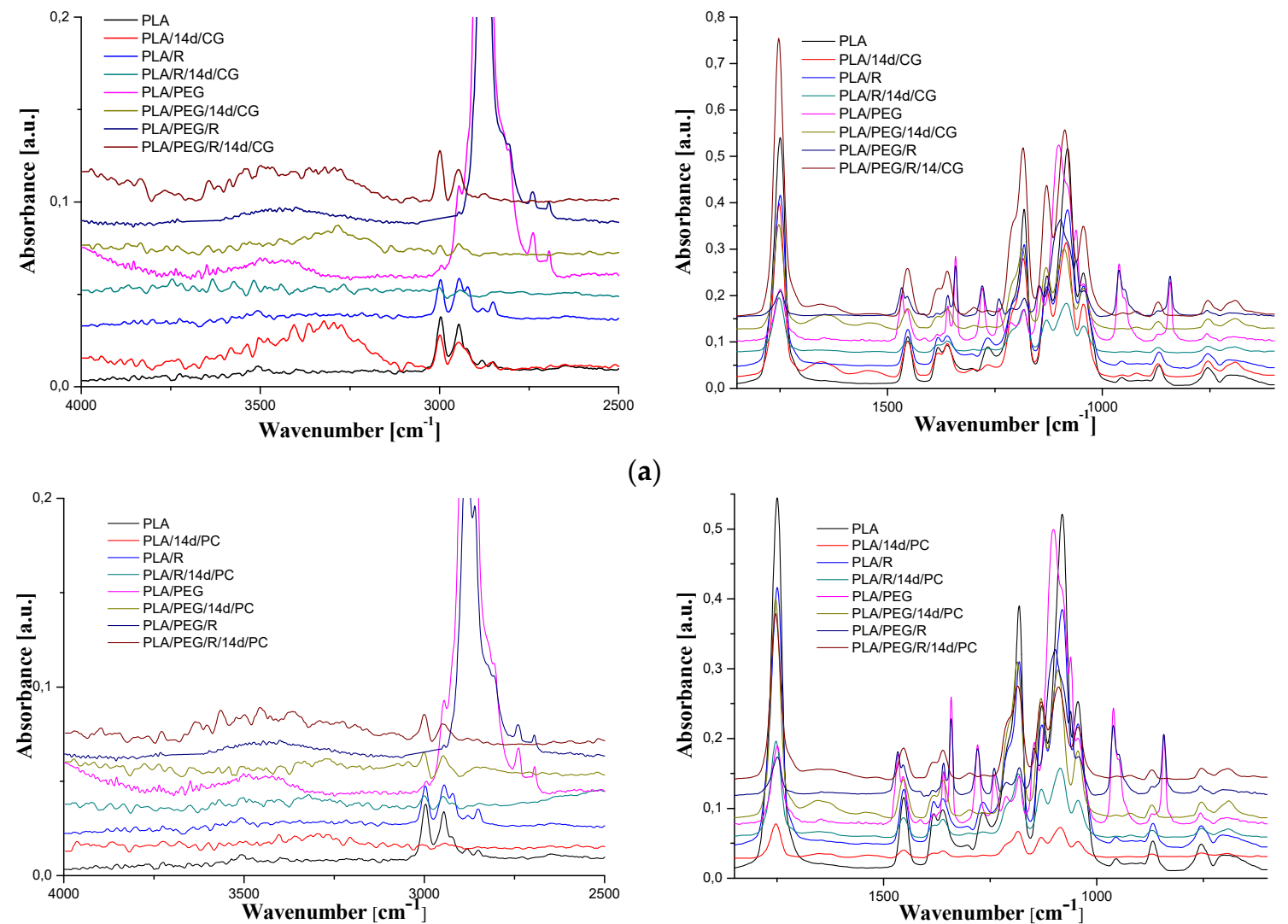

(a)

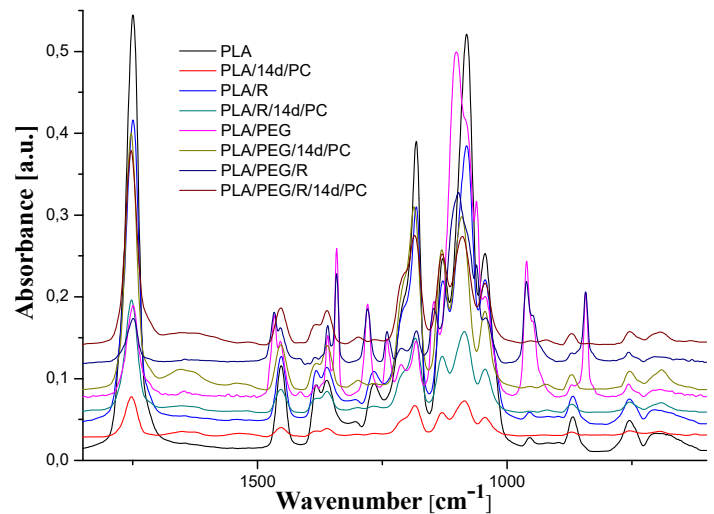

(b)

Figure 8. FTIR spectra of PLA-based samples before and after 14 days fungal exposure to: (a) Chaetomium globosum and (b) Phanerochaete chrysosporium.

The general band assignments for PLA-based samples was done according to literature data $[25,54,55]$ and are presented in Table 4 . As revealed in our previous studies $[29,30,56]$, neat PLA exhibits sharp bands assigned to vibrations of carbonyl group, $v_{\mathrm{C}=\mathrm{O}}$, with a maximum at $1749 \mathrm{~cm}^{-1}$ (stretching) and at $1266 \mathrm{~cm}^{-1}$ (bending). The absorption bands of native PLA are also noticed in the spectrum of the fungal-biodegraded PLA but slightly shifted to higher wavenumbers and with changes in intensities, and new bands also appears. The spectra of neat PLA, PLA/R, PLA/PEG and PLA/PEG/R samples after being exposed to fungi had a shift in the bands corresponding to $C=O$ group to higher wavenumbers from $1749 \mathrm{~cm}^{-1}$ to $1754 \mathrm{~cm}^{-1}$ depicting a reduction in their molecular weights. In the case of biodegraded neat PLA sample new bands appear, at 3323, 1652, 1546, $920 \mathrm{~cm}^{-1}$, for Chaetomium globosum fungus and at $3498,1654,1631,1523,921 \mathrm{~cm}^{-1}$ for PLA exposed to Phanerochaete chrysosporium. The mentioned bands above are assigned to $-\mathrm{OH}$ stretching, amide $\mathrm{C}=\mathrm{O}$ stretching, $\mathrm{N}-\mathrm{H}$ bending and helical backbone vibrations with the $\mathrm{CH}_{3}$ rocking modes, respectively. In the case of all biodegraded PLA-based samples, with both fungi, arises in the FTIR spectra a new band at $920-921 \mathrm{~cm}^{-1}$ that is characteristic to crystalline phase (namely $\alpha$-crystals) [57], being accompanied also by a decrease in the intensity of the amorphous band at $955 \mathrm{~cm}^{-1}$. This finding indicates that exposure of PLA-based samples to fungal environment determines an increase in crystallinity, which may be assigned to changes in the amorphous/crystalline (more stable to degradation) fraction ratio, being known that the degradation firstly occurs in amorphous region, or to the reorganization of the remaining undegraded chains with lower molecular length because of the molecular weight decrease, which can crystallize [25,58].

For PLA/PEG sample the bands assigned to $\mathrm{C}-\mathrm{O}$ stretching mode were merged in the very broad envelope centered on 1182 and $1101 \mathrm{~cm}^{-1}$ arising from $\mathrm{C}-\mathrm{O}, \mathrm{C}-\mathrm{O}-\mathrm{C}$ stretches and $\mathrm{C}-\mathrm{O}-\mathrm{H}$ bends vibrations of PEG in PLA. After fungal degradation, first band mentioned is shifted at higher 
wavenumbers, while the second one is displaced at lower wavenumbers, meaning that oxygen containing bonds suffers changes by fungal action. Furthermore, for the initial samples containing PEG (PLA/PEG and PLA/PEG/R) a characteristic band is observed at $842-843 \mathrm{~cm}^{-1}$ that is assigned to $\mathrm{C}-\mathrm{O}$ stretching, and $\mathrm{CH}_{2}$ rocking. After incubation with fungi this band disappears indicating that the addition of the hydrophilic plasticizer leads to an increased susceptibility to biodegradation of the PLA, acting as zones of adhesion for fungi.

Table 4. FTIR spectroscopy data and the band assignment.

\begin{tabular}{|c|c|c|c|c|c|c|c|c|c|c|c|c|}
\hline \multicolumn{12}{|c|}{ Bands Wavenumber $\left(\mathrm{cm}^{-1}\right)$} & \multirow{3}{*}{$\begin{array}{c}\text { Band } \\
\text { Assignment }\end{array}$} \\
\hline \multicolumn{3}{|c|}{ PLA } & \multicolumn{3}{|c|}{ PLA/PEG } & \multicolumn{3}{|c|}{ PLA/R } & \multicolumn{3}{|c|}{ PLA/PEG/R } & \\
\hline Undegraded & \multicolumn{2}{|c|}{ Degraded } & Undegraded & \multicolumn{2}{|c|}{ Degraded } & Undegraded & \multicolumn{2}{|c|}{ Degraded } & Undegraded & \multicolumn{2}{|c|}{ Degraded } & \\
\hline- & - & 3498 & 3437 & - & - & 3511 & 3518 & - & - & - & 3564 & $v(\mathrm{OH})$ free \\
\hline- & 3323 & - & - & 3282 & 3271 & - & - & 3350 & 3399 & 3402 & 3359 & $\begin{array}{c}v(\mathrm{OH}) \\
\text { H-bonded }\end{array}$ \\
\hline- & - & - & 2884 & - & - & - & - & - & 2884 & - & - & $v \mathrm{CH}$ \\
\hline 1749 & 1753 & 1754 & 1749 & 1754 & 1754 & 1750 & 1755 & 1754 & 1749 & 1754 & 1754 & $v(\mathrm{C}=\mathrm{O})$ \\
\hline- & 1652 & 1654 & - & 1647 & 1654 & - & 1666 & 1635 & - & 1654 & 1627 & $\operatorname{Amide}(\mathrm{C}=\mathrm{O})$ \\
\hline- & - & 1631 & - & - & - & - & - & 1584 & - & - & - & $v \mathrm{NH}$ \\
\hline- & 1546 & 1523 & - & 1542 & 1541 & - & 1523 & 1519 & - & 1527 & 1517 & $v \mathrm{NH}$ \\
\hline- & - & - & 1467 & - & - & - & - & & 1467 & - & - & $\mathrm{CH}$ bending \\
\hline- & - & - & 1341 & - & - & - & - & - & 1341 & - & - & $\delta_{\mathrm{s}} \mathrm{CH}_{3}$ \\
\hline 1303 & 1299 & 1299 & 1279 & 1298 & 1298 & 1302 & 1299 & 1298 & 1280 & 1298 & 1298 & $\delta 2 \mathrm{CH}$ \\
\hline 1266 & 1267 & 1267 & 1240 & 1267 & 1267 & 1267 & 1267 & 1265 & 1240 & 1267 & 1265 & $\delta \mathrm{CH}+v \mathrm{COC}$ \\
\hline 1211 & 1209 & 1211 & 1212 & 1209 & 1209 & 1210 & 1209 & 1210 & 1211 & 1209 & 1210 & $v_{\mathrm{as}} \mathrm{COC}$ \\
\hline 1182 & 1184 & 1184 & 1182 & 1186 & 1186 & 1182 & 1184 & 1184 & 1181 & 1184 & 1186 & $v_{\mathrm{as}} \mathrm{COC}$ \\
\hline 1129 & 1130 & 1130 & 1146 & 1130 & 1130 & 1129 & 1130 & 1130 & 1146 & 1130 & 1130 & $\mathrm{r}_{\mathrm{as}} \mathrm{CH}_{3}$ \\
\hline 1081 & 1083 & 1085 & 1101 & 1089 & 1091 & 1081 & 1083 & 1085 & 1097 & 1087 & 1089 & $v_{\mathrm{s}} \mathrm{COC}$ \\
\hline- & - & - & 1061 & - & - & - & - & - & 1060 & - & - & vCOC \\
\hline 1044 & 1043 & 1045 & 1044 & 1043 & 1045 & 1044 & 1043 & 1045 & 1042 & 1043 & 1043 & $v \mathrm{C}-\mathrm{CH}_{3}$ \\
\hline 954 & 955 & 954 & 961 & 954 & 954 & 954 & 952 & 954 & 961 & 952 & 953 & $\mathrm{rCH}_{3}+v \mathrm{CC}$ \\
\hline- & 920 & 921 & 948 & 920 & 921 & & 921 & 921 & 949 & 921 & 921 & $\mathrm{rCH}_{3}+v \mathrm{CC}$ \\
\hline 867 & 869 & 869 & 870 & 869 & 869 & 868 & 869 & 869 & 871 & 869 & 869 & $v \mathrm{C}-\mathrm{COO}$ \\
\hline
\end{tabular}

CG-Chaetomium globosum, PC—Phanerochaete chrysosporium, s-symmetrical and as-asymmetric; $v$-in plane vibration; $\gamma$-out of plane vibration; $r$-rocking vibration; $\delta_{\mathrm{s}}$ - scissoring vibration.

FTIR spectra of samples before biodegradation showed the absorbance of $\mathrm{CH}-\mathrm{COC}$ bonding increased with PEG addition into PLA matrix at frequency $1270 \mathrm{~cm}^{-1}$ (a shift to higher wavenumbers, $1279 \mathrm{~cm}^{-1}$, being also observed) indicating that binding interaction occurred between PLA and PEG. After incubation with fungi this band suffers a sharp decrease in intensity, revealing that the chemical integrity of the blends is affected. Specific to the samples incubated with the fungi was found also the splitting of the band at around $1453 \mathrm{~cm}^{-1}$, attributed to methyl C-H asymmetric bend, which is recently associated with the oxidation and degradation of polymeric materials [59].

\subsection{Thermal Behavior}

The glass transition temperature $\left(T_{\mathrm{g}}\right)$, melt temperature $\left(T_{\mathrm{m}}\right)$, crystallization temperature $\left(T_{\mathrm{cc}}\right)$, enthalpy of endothermal melting $\left(\Delta H_{\mathrm{m}}\right)$ and degree of crystallization $\left(X_{\mathrm{c}}\right)$ of samples obtained by DSC technique, before and after fungal degradation were determined.

The DSC curves of PLA and PLA/PEG based samples before and after biodegradation (PLA/14d/CG and PLA/14d/PC) in the presence of the two fungi, PC and CG, were shown in Figure 9 and the values of determined thermal events were summarized in Table 5 . 


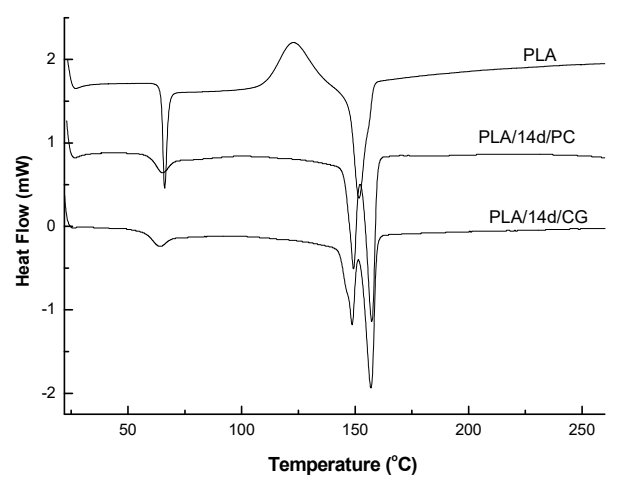

(a)

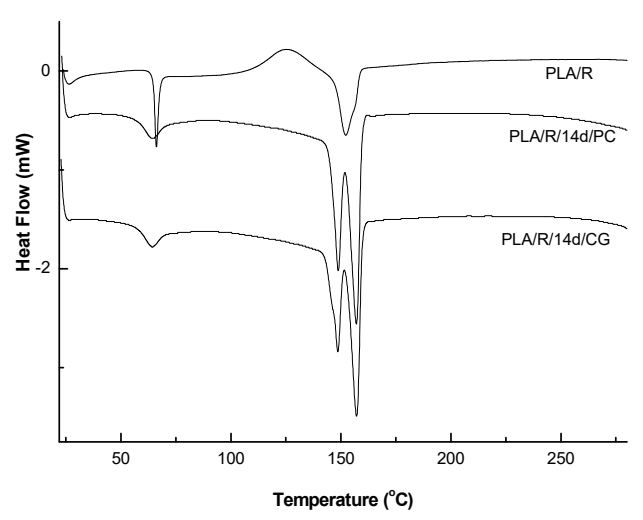

(c)

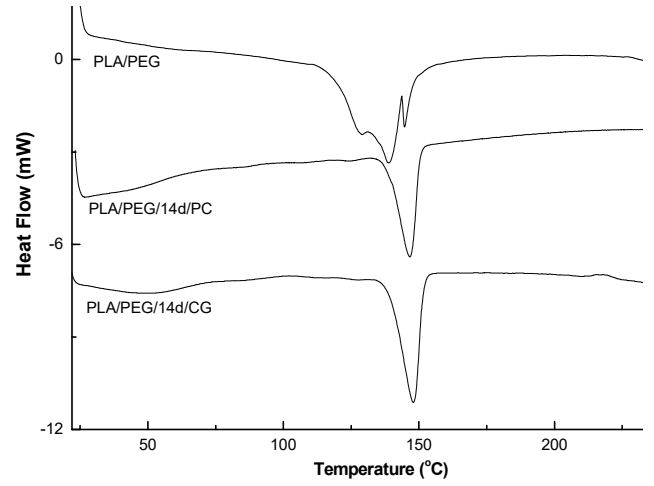

(b)

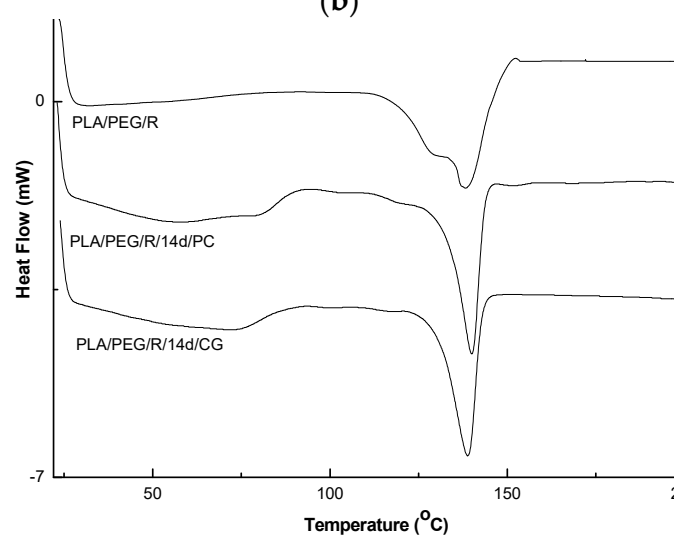

(d)

Figure 9. Differential scanning calorimetry (DSC) curves of undegraded and biodegraded PLA (a), PEG-plasticized PLA (b); PLA/R (c); PLA/PEG/R (d).

Table 5. Thermal characteristics of the PLA based systems before and after fungal degradation determined by DSC.

\begin{tabular}{|c|c|c|c|c|c|}
\hline Samples Code & $T_{\mathrm{g}}\left({ }^{\circ} \mathrm{C}\right)$ & $T_{\mathrm{cc}}\left({ }^{\circ} \mathrm{C}\right)$ & $T_{\mathrm{m}}$ & $\Delta H_{\mathrm{m}}(\mathrm{J} / \mathrm{g})$ & $X_{\mathrm{c}}(\%)$ \\
\hline PLA & 66 & 123.0 & 151.8 & -10.23 & 11.05 \\
\hline PLA/14d/CG & 64.1 & & $\begin{array}{c}\text { Two peaks } 148.7 \\
156.9\end{array}$ & $\begin{array}{l}-12.13 \\
-18.37\end{array}$ & 32.76 \\
\hline PLA/14d/PC & 65.3 & & $\begin{array}{c}\text { Two peaks } \\
149.3 \\
157.3\end{array}$ & $\begin{array}{l}-13.98 \\
-19.26\end{array}$ & 35.70 \\
\hline PLA/PEG & 44.4 & & $\begin{array}{c}128.9 \mathrm{sh} \\
138.9 \\
144.7 \mathrm{sh}\end{array}$ & -26.21 & 28.15 \\
\hline PLA/PEG/14d/CG & 50.3 & & 147.9 & -53.76 & 57.73 \\
\hline PLA/PEG/14d/PC & 46.5 & & 146.6 & -44.39 & 47.95 \\
\hline PLA/R & 66.2 & 125.4 & 152.2 & $\begin{array}{c}7.81 \\
-13.09\end{array}$ & 14.06 \\
\hline PLA/R/14d/CG & 64.4 & & $\begin{array}{c}\text { Two peaks } 148.6 \\
157.1\end{array}$ & $\begin{array}{l}-13.73 \\
-17.53\end{array}$ & 33.57 \\
\hline PLA/R/14d/PC & 64.4 & & $\begin{array}{c}\text { Two peaks } 148.7 \\
157.0\end{array}$ & $\begin{array}{l}-18.74 \\
-17.69\end{array}$ & 39.13 \\
\hline PLA/PEG/R & 48.4 & & $\begin{array}{c}129.0 \mathrm{sh} \\
138.3\end{array}$ & -12.03 & 12.92 \\
\hline PLA/PEG/R/14d/CG & 49.5 & & 138.8 & -61.43 & 65.98 \\
\hline PLA/PEG/R/14d/PC & 46 & & $\begin{array}{c}\text { Two peaks } 116.0 \\
139.9\end{array}$ & -49.52 & 53.19 \\
\hline
\end{tabular}


As depicted in Figure 9a, PLA showed the glass transition at $66^{\circ} \mathrm{C}$, cold crystallization temperature at $123.0^{\circ} \mathrm{C}$, which is also present only in DSC curve of the PLA/R sample, and single large melting peak at $152{ }^{\circ} \mathrm{C}$. When the PLA was exposed to the action of the two fungi, very important changes in thermal characteristics were clearly visible. The $T_{\mathrm{g}}$ values slightly decrease, $T_{\mathrm{cc}}$ was not more present in DSC curves, while melting peak is split into two melting peaks at $148^{\circ} \mathrm{C}$ and $157^{\circ} \mathrm{C}$ for PLA/14d/CG and at 150 and $157^{\circ} \mathrm{C}$ for PLA/14d/PC, respectively. The two melting peaks observed may result from the melting of two different crystals of PLA which was broken after the action of fungi as the GPC results also proved by decrease of average molecular weight. The shorter chains resulted after degradation can easily reorganize in different crystallites type and this is evident by the two melting peaks in DSC curves and significant increase in crystallinity index $X_{\mathrm{c}}$ from $11.05 \%$ to $32.76 \%$ and to $35.70 \%$ for PLA/14d/CG and PLA/14d/PC, respectively. A similar melting behavior of PLA was reported by $\mathrm{Su}$ et al. [60] and also in our previous paper related to degradation of PLA systems by soil burial [30]. Biodegradation of PLA in the presence of Chaetomium globosum was also studied by Ding et al. [61]. The fungi effect on PLA was reported as taking place firstly on the surface and then gradually degraded under fungi environment leading to the decline of tensile and bending properties.

By plasticizing of PLA with PEG, the thermal characteristics resulted in a decrease of $T_{\mathrm{g}}=44.4^{\circ} \mathrm{C}$ and a complex melting peak with two shoulders at $128.9^{\circ} \mathrm{C}$ and $144.7^{\circ} \mathrm{C}$ and average $T_{\mathrm{m}}=138.9^{\circ} \mathrm{C}$-Figure $9 \mathrm{~b}$. A high crystallinity degree was found of $28.15 \%$, as also reported before in a previous study [56]. A shift in the glass transition was observed after fungi action at $50.3^{\circ} \mathrm{C}$ in the case of PLA/PEG/14d/CG and at $59^{\circ} \mathrm{C}$ in the case of PLA/PEG/14d/PC, respectively. The single melting peaks remain almost at the same temperature of about $147^{\circ} \mathrm{C}$ but the shoulders are not more shown by DSC curves. This could be explain by a simpler composition of the samples after fungal degradation by the loss of PEG and/or the progress of degradation the which also allows the occurrence of the crystallization process and therefore the $X_{\mathrm{c}}$ significantly increases up to $48 \%-58 \%$.

The thermal behavior of the PLA/R and PLA/PEG/R samples is similar with those of PLA and PLA/PEG ones, respectively. Finally, the fungal degradation led to increase of the melting in two steps and to the increase in $X_{\mathrm{c}}$. The biodegraded matrices, PLA/R/14d/CG and PLA/R/14d/PC presented a melting peak split in two distinct melting peaks which may be ascribed to recrystallization of the fragments resulted under fungi action. A similar behavior was found also by Musuc et al. in the case of addition of rosemary to polyethylene films and irradiated [62].

The effect of the fungi on the structure was evidenced by the disappearance of the shoulder and the determined thermal events are shifted indicating presence of smaller molecules which crystalize leading to higher crystallinity. Backes et al. [63] observed a similar phenomenon during the study of PLA/Biosilicate composites and concluded that the crystallization of PLA occurs easier in degraded systems with greater mobility. This outcome can support the hypothesis that after biodegradation in the presence of the two fungi, the chains of PLA/PEG/R became shorter in accordance with GPC results.

\subsection{Thermogravimetry (TG/DTG) Results}

The thermal behavior at high temperatures of PLA matrix before and after biodegradation in the presence of CG and PC fungi was represented in Figure 10 and data are summarized in Table 6. 

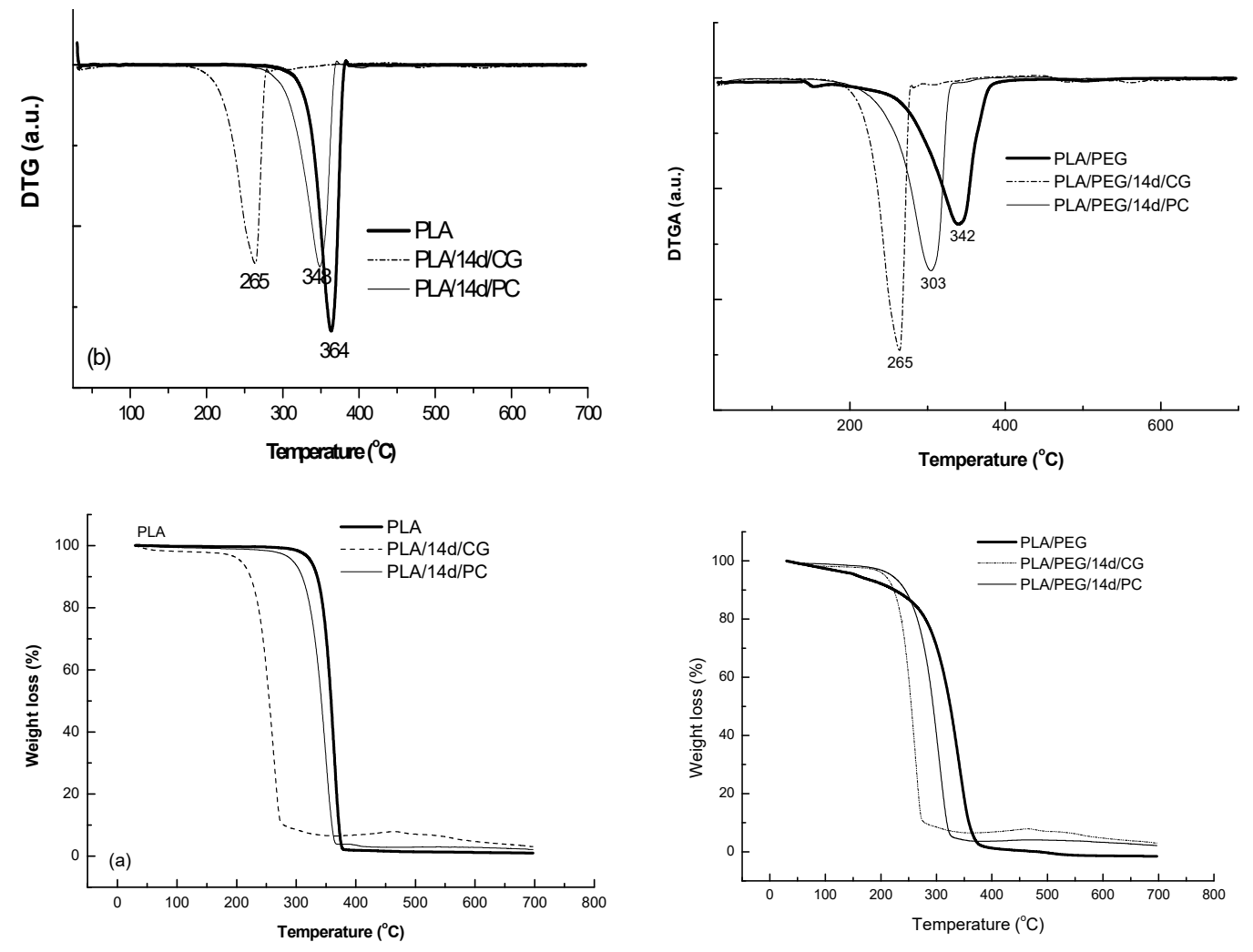

(a)

(b)

Figure 10. Thermogravimetry (TG/DTG) curves of PLA (a) and PLA/PEG (b) based systems before and after biodegradation.

Table 6. Thermal characteristics of the PLA and PLA/PEG based systems determined by TG.

\begin{tabular}{ccccc}
\hline \multirow{2}{*}{ Samples Code } & \multicolumn{5}{c}{ TG/DTG Results } \\
\cline { 2 - 5 } & $\mathbf{T}_{\text {onset }}\left({ }^{\circ} \mathbf{C}\right)$ & $\mathbf{T}_{\text {peak }}\left({ }^{\circ} \mathbf{C}\right)$ & $\mathbf{T}_{\mathbf{f}}\left({ }^{\circ} \mathbf{C}\right)$ & $\Delta \mathbf{m}$ (\%) \\
\hline PLA & 279 & 362 & 383 & 98.3 \\
\hline PLA/14d/CG & 235 & 357 & 384 & 91.52 \\
\hline PLA/14d/PC & 248 & 350 & 367 & 95 \\
\hline PLA/PEG & 152 & 342 & 392 & 95 \\
\hline PLA/PEG/14d/CG & 156 & 265 & 327 & 90.33 \\
\hline PLA/PEG/14d/PC & 157 & 303 & 367 & 93.9 \\
\hline PLA/R & 282 & 362 & 390 & 94.0 \\
\hline PLA/R/14d/CG & 393 & $417 s$ & 438 & 95.66 \\
\hline PLA/R/14d/PC & 251 & 356 & 382 & 94.75 \\
\hline PLA/PEG/R & 243 & 352 & 371 & 13.43 \\
& 106 & 146 & 180 & 84.87 \\
\hline PLA/PEG/R/14d/CG & 244 & $364 ; 405 s h$ & 436 & 2.27 \\
& 108 & 132 & 149 & 88.6 \\
& 160 & 287 & 316 & 3.99 \\
\hline & 325 & 355 & 382 & 5.08 \\
\hline PLA/PEG/R/14d/PC & 455 & 482 & 507 & 2.66 \\
& 111 & 143 & 143 & 0.89 \\
\hline
\end{tabular}

$\mathrm{T}_{\text {onset }}$ - onset temperatures, $\mathrm{T}_{\text {peak }}$-temperature corresponding to maximum mass loss rate, $\mathrm{T}_{\mathrm{f}}$ - final temperature of process and $\Delta \mathrm{m}$-mass loss at the end of each process); sh-shoulder. 
PLA sample decomposed in a single step between $279-383^{\circ} \mathrm{C}$, with a mass loss of $98 \%$, results being confirmed by previously reported study [57]. PLA samples exposed to the fungi environment showed a lower thermal stability with a mass loss of $91.5 \%$ and $95 \%$ for CG and PC, respectively.

The plasticized PLA with PEG showed even lower thermal stability by comparison with PLA-Figure 10, PLA/PEG showing a main degradation step between $220-392{ }^{\circ} \mathrm{C}$, where $95 \%$ of its mass is lost. PLA/PEG/CG and PLA/PEG/PC showed different degradation profiles. CG seemed to have a stronger effect on the polymeric chains, the product after fungal degradation being more susceptible to thermal degradation.

Addition of rosemary extract to PLA matrices slightly increased the thermal stability, $\mathrm{T}_{\text {onset }}=282{ }^{\circ} \mathrm{C}$, the DTG peak temperature was found to the same value of $362{ }^{\circ} \mathrm{C} ; \mathrm{T}_{\mathrm{f}}$ of PLA/R was found also slightly higher of $390{ }^{\circ} \mathrm{C}$ and the degraded mass being of $94 \%$. A small second degradation step was detected at higher temperature over $390^{\circ} \mathrm{C}$ which could be assigned to the degradation of the products resulted from first step of degradation. The two fungi used for biodegradation of PLA/R matrices seemed to act in a similar manner on this sample, as no significant differences were observed.

The TG/DTG curves of the PEG-plasticized PLA with incorporated rosemary extract show two degradation steps-Figure 11 , the main one occurring between $244-436{ }^{\circ} \mathrm{C}$ with a main degradation peak split in one peak and a shoulder at $405{ }^{\circ} \mathrm{C}$; PLA/PEG/R lost during the main degradation step $85 \%$ from its mass. A small mass loss of $13.4 \%$ occurs at low temperature from $106{ }^{\circ} \mathrm{C}$ to $180{ }^{\circ} \mathrm{C}$ probably because of desorption of water or of evolved low molecular weight compounds. After fungal degradation, the resulted products showed a much lower thermal stability and a complex mechanism of thermal degradation evidenced by shoulders in DTG curves both before and after main degradation step which take place $160-320^{\circ} \mathrm{C}$ with a mass loss of $88 \%$.
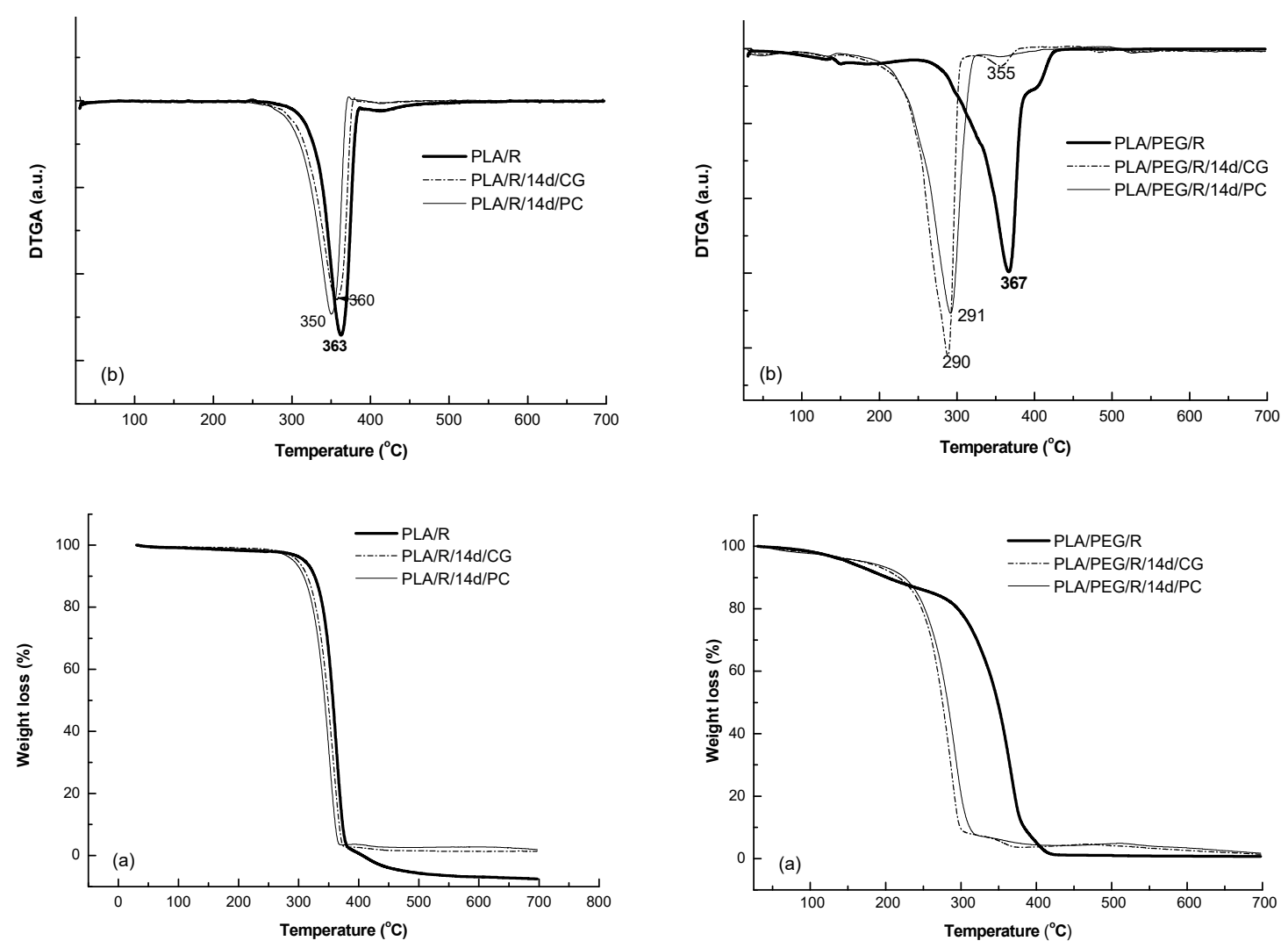

(a)

(b)

Figure 11. TG/DTG curves of PLA/R (a) and PLA/PEG/R samples before and after biodegradation (a) TG curves and (b) first derivative DTG curves. 


\section{Conclusions}

Two fungal strains, Chaetomium globosum and Phanerochaete chrysosporium, were tested for their ability to biodegrade complex polymeric systems based on PLA and natural bioactive compounds (chitosan and powdered rosemary alcoholic extract). The fungi extracellular enzyme activities (e.g., catalase, superoxide dismutase) are slightly decreased in the case of composites containing natural additives. The presence of natural compounds in the PLA-based polymeric systems determines an acceleration of fungal degradation and probably the chemical hydrolysis, which further helps the attachment of fungi to the resulting polymeric fragments and consequently the acceleration of biodegradation. Significant decreases in average molecular mass of the polymeric samples were observed by fungi action; accompanied by structural changes, increase in crystallinity and decrease of thermal properties, the loss of the physical integrity and finally to degradation with integration in environmental medium. Such findings are in accordance with other reports on microbial degradation of polymeric materials which offer new emerging technological opportunities to treat the enormous pollution problems arising by the use of polymeric products. Degrading fungi (some found in soil), as Aspergillus tubingensis [64], showed the ability to biodegrade various polymers. Both fungi tested here proved to be efficient for PLA-based material degradation, the best from them being Chaetomium globosum.

Author Contributions: Investigation, E.S., L.O., O.Y.; methodology, C.V. and L.O.; writing—original draft, E.S., L.O. and C.V. All authors have read and agreed to the published version of the manuscript.

Funding: This research was funded through the project Development of the national RD system, Subprogram 1.2-Institutional Performance-RDI excellence funding projects, by the Ministry of Research and Innovation within Program 1. Contract no.34PFE/19.10.2018.

Acknowledgments: The support of Catalina-Natalia Yilmaz for thermal properties experiments is acknowledged. We are also grateful to Chem. Dorina Anghel and Ph.D. student Daniela Rusu for their support in recording GPC and SEM data.

Conflicts of Interest: The authors declare no conflict of interest.

\section{References}

1. Moharir, R.V.; Kumar, S. Challenges associated with plastic waste disposal and allied microbial routes for its effective degradation: A comprehensive review. J. Clean. Prod. 2019, 208, 65-76. [CrossRef]

2. Majid, I.; Thakur, M.; Nanda, V. Biodegradable Packaging Materials. Available online: https://doi.org/10. 1016/b978-0-12-803581-8.10356-x (accessed on 17 February 2020).

3. Muniyasamy, S.; Ofosu, O.; Jacob John, M.; Anandjiwala, R.D. Mineralization of poly(lactic acid) (PLA), poly(3-hydroxybutyrate-co-valerate) (PHBV) and PLA/PHBV Blend in compost and soil environments. J. Renew. Mater. 2016, 4, 133-145. [CrossRef]

4. Ohkita, T.; Lee, S.H. Thermal degradation and biodegradability of poly(lactic acid)/corn starch biocomposites. J. Appl. Polym. Sci. 2006, 100, 3009-3017. [CrossRef]

5. Muniyasamy, S.; Ofosu, O.; John, M.J.; Anandjiwala, R.D. Mineralization of Poly(lactic acid) (PLA), Poly (3-hydroxybutyrate-co-valerate) (PHBV) and PLA/PHBV Blend in Compost and Soil Environments. Project: Compostability and Biodegradation of Bioplastics and Biocomposites. January 2016. Available online: https://www.researchgate.net/publication/304615824 (accessed on 23 January 2020).

6. Available online: https://all3dp.com/2/is-pla-biodegradable-what-you-really-need-to-know/ (accessed on 17 February 2020).

7. Tsuji, H.; Miyauchi, S. Enzymic Hydrolysis of Polylactic Acid. Engineering in Medicine. Biomacromolecules 2001, 2, 597-604. [CrossRef]

8. Ratner, B.D.; Hoffman, A.S.; Schoen, F.J.; Lemons, J.E. Biomaterials Science: An Introduction to Materials in Medicine 2013, 3rd ed.; Academic Press: Oxford, UK, 2013; Available online: http://www.sciencedirect.com/ science/book/9780123746269 (accessed on 23 January 2020).

9. Nampoothiri, K.M.; Nair, N.R.; John, R.P. An overview of the recent developments in polylactide (PLA) research. Bioresour. Technol. 2010, 101, 8493-8501. [CrossRef] 
10. Qi, X.; Rena, Y.; Wang, X. New advances in the biodegradation of Poly (lactic) acid. Int. Biodeterior. Biodegrad. 2017, 117, 215-223. [CrossRef]

11. Lim, H.-A.; Raku, T.; Tokiwa, Y. Hydrolysis of polyesters by serine proteases. Biotechnol. Lett. 2005, 27, 459-464. [CrossRef]

12. Tokiwa, Y.; Calabia, B.P. Biodegradability and biodegradation of poly (lactide). Appl. Microbiol. Biotechnol. 2006, 72, 244-251. [CrossRef]

13. Kawai, F.; Nakadai, K.; Nishioka, E.; Nakajima, H.; Ohara, H.; Masaki, K.; Iefuji, H. Different enantioselectivity of two types of poly (lactic acid) depolymerases toward poly(l-lactic acid) and poly(d-lactic acid). Polym. Degrad. Stab. 2011, 96, 1342-1348. [CrossRef]

14. Apinya, T.; Sombatsompop, N.; Prapagdee, B. Selection of a Pseudonocardia sp. RM423 that accelerates the biodegradation of poly (lactic) acid in submerged cultures and in soil microcosms. Int. Biodeterior. Biodegrad. 2015, 99, 23-30. [CrossRef]

15. Kawai, F. Polylactic Acid (PLA)-degrading Microorganisms and PLA Depolymerases. In Green Polymer Chemistry: Biocatalysis and Biomaterials; ACS Symposium Series; American Chemical Society: Washington DC, USA, 2010; Chapter 27; Volume 1043, pp. 405-414. ISBN 9780841225817. eISBN: 9780841225824.

16. Vimala, P.; Mathew, L. Biodegradation of polyethylene using bacillus subtilis. Procedia Technol. 2016, 24, 232-239. [CrossRef]

17. Pattanasuttichonlakul, W.; Sombatsompop, N.; Prapagdee, B. Accelerating biodegradation of PLA using microbial W. consortium from dairy wastewater sludge combined with PLA-degrading bacterium. Int. Biodeterior. Biodegrad. 2018, 132, 74-83. [CrossRef]

18. Jarerat, A.; Tokiwa, Y. Degradation of poly (L-lactide) by a fungus. Macromol. Biosci. 2001, 1, 136-140. [CrossRef]

19. Karamanlioglu, M.; Houlden, A.; Robson, G.D.; Karamanlioglu, M. Isolation and characterisation of fungal communities associated with degradation and growth on the surface of poly (lactic) acid (PLA) in soil and compost. Int. Biodeterior. Biodegrad. 2014, 95, 301-310. [CrossRef]

20. Saadi, Z.; Rasmont, A.; Cesar, G.; Bewa, H.; Benguigui, L. Fungal degradation of poly(L-lactide) in soil and in compost. J. Polym. Environ. 2012, 20, 273-282. [CrossRef]

21. Vivi, V.K.; Martins-Franchetti, S.M.; Attili-Angelis, D. Biodegradation of PCL and PVC: Chaetomium globosum (ATCC 16021) activity. Folia Microbiol. 2019, 64, 1-7. [CrossRef]

22. Wanmolee, W.; Sornlake, W.; Rattanaphan, N.; Suwannarangsee, S.; Laosiripojana, N.; Champreda, V. Biochemical characterization and synergism of cellulolytic enzyme system from Chaetomium globosum on rice straw saccharification. BMC Biotechnol. 2016, 16, 82. [CrossRef]

23. Zhai, X.; Luo, D.; Li, X.; Han, T.; Jia, M.; Kong, Z.; Ji, J.; Rahman, K.; Qin, L.; Zheng, C. Endophyte chaetomium globosum D38 promotes bioactive constituents accumulation and root production in salvia miltiorrhiza. Front. Microbiol. 2018, 8, 2694. [CrossRef]

24. Morel, M.; Ngadin, A.A.; Jacquot, J.-P.; Gelhaye, É. Reactive oxygen species in Phanerochaete chrysosporium relationship between extracellular oxidative and intracellular antioxidant systems. Adv. Bot. Res. 2009, 52, 153-186.

25. Stoleru, E.; Hitruc, E.G.; Vasile, C.; Oprica, L. Biodegradation of poly (lactic acid)/chitosan stratified composites in presence of the Phanerochaete chrysosporium fungus. Polym. Degrad. Stab. 2017, 143, 118-129. [CrossRef]

26. Lipsa, R.; Tudorachi, N.; Darie-Nita, R.N.; Oprică, L.; Vasile, C.; Chiriac, A. Biodegradation of poly(lactic acid) and some of its based systems with Trichoderma viride. Int. J. Biol. Macromol. 2016, 88, 515-526. [CrossRef] [PubMed]

27. Durazzo, A.; Lucarini, M.; Souto, E.; Cicala, C.; Caiazzo, E.; Izzo, A.A.; Novellino, E.; Santini, A. Polyphenols: A concise overview on the chemistry, occurrence, and human health. Phytother. Res. 2019, 33, 2221-2243. [CrossRef] [PubMed]

28. Durazzo, A.; D’Addezio, L.; Camilli, E.; Piccinelli, R.; Turrini, A.; Marletta, L.; Marconi, S.; Lucarini, M.; Lisciani, S.; Gabrielli, P.; et al. From plant compounds to botanicals and back: A current snapshot. Molecules 2018, 23, 1844. [CrossRef] [PubMed]

29. Vasile, C.; Stoleru, E.; Darie-Nita, R.N.; Dumitriu, R.P.; Pamfil, D.; Tartau, L. Biocompatible materials based on plasticized Poly (lactic acid), chitosan and rosemary ethanolic extract I. Effect of chitosan on the properties of plasticized Poly (lactic acid) materials. Polymers 2019, 11, 941. [CrossRef] 
30. Vasile, C.; Pamfil, D.; Râpă, M.; Darie-Niţă, R.N.; Mitelut, A.C.; Popa, E.E.; Popescu, P.A.; Draghici, M.C.; Popa, M.E. Study of the soil burial degradation of some PLA/CS biocomposites. Compos. Part B Eng. 2018, 142, 251-262. [CrossRef]

31. Manoliu, A.; Balan, M.; Oprica, L.; Grădinaru, P. The evolution of catalase and peroxidase activity in Phanerochaete chrysosporium grown on media containing beech and fir sawdust and under the influence of some amino acids. Analele Ştiinţifice ale Universităţii Alexandru Ioan Cuza Secţiunea Genetică si Biologie Moleculară 2010, XI, 47-52.

32. Sinha, A.K. Colorimetric assay of catalase. Anal. Biochem. 1972, 47, 389-394. [CrossRef]

33. Hodges, D.M.; DeLong, J.M.; Forney, C.F.; Prange, R.K. Improving the thiobarbituric acid-reactive-substances assay for estimating lipid peroxidation in plant tissues containing anthocyanin and other interfering compounds. Planta 1999, 207, 604-611. [CrossRef]

34. Bradford, M.M. A rapid and sensitive method for microgram quantities of protein utilizing the principle of protein-dye binding. Anal. Biochem. 1976, 72, 248-254. [CrossRef]

35. Auras, R.A.; Singh, S.P.; Singh, J.J. Evaluation of oriented poly (lactide) polymers vs. existing PET and oriented PS for fresh food service containers. Packag. Technol. Sci. 2005, 18, 207-216. [CrossRef]

36. Shah, A.A.; Hasan, F.; Hameed, A.; Ahmed, S. Biological degradation of plastics: A comprehensive review. Biotechnol. Adv. 2008, 26, 246-265. [CrossRef] [PubMed]

37. da Silva Gois, G.; de Andrade, M.F.; Silva Garcia, S.M.; Vinhas, G.M.; Santos, A.S.F.; Medeiros, E.S.; Oliveira, J.E.; de Almeida, Y.M.B. Soil biodegradation of PLA/CNW nanocomposites modified with ethylene oxide derivatives. Mater. Res. 2017, 20 (Suppl. 2), 899-904. [CrossRef]

38. Tsuji, H.; Miyauchi, S. Enzymatic hydrolysis of poly (lactide) s: Effects of molecular weight, L-lactide content, and enantiomeric and diastereoisomeric polymer blending. Biomacromolecules. 2001, 2, 597-604. [CrossRef] [PubMed]

39. Geweely, N.S.; Ouf, S.A. Enhancement of fungal degradation of starch based plastic polymer by laser-induced plasma. Afr. J. Microbiol. Res. 2011, 5, 3273-3281.

40. Odebode, A.; Adekunle, A. Biomarkers of oxidative stress as indicators of fungi environmental pollution in Balb/c albino mice monitored from South West. Niger. J. Pathog. 2019, 2019, 6561520. [CrossRef]

41. Hancock, J.T.; Desikan, R.; Neill, S.J. Role of reactive oxygen species in cell signalling pathways. Biochem. Biomed. Asp. Oxidative Modif. 2001, 29, 345-349. [CrossRef]

42. Das, K.; Roychoudhury, A. Reactive oxygen species (ROS) and response of antioxidants as ROS-scavengers during environmental stress in plants. Front. Environ. Sci. 2014, 2, 53. [CrossRef]

43. Cavia-Saiz, M.; Busto, M.D.; Pilar-Izquierdo, M.C.; Ortega, N.; Perez-Mateos, M.; Muñiz, P. Antioxidant properties, radical scavenging activity and biomolecule protection capacity of flavonoid naringenin and its glycoside naringin: A comparative study. J. Sci. Food Agric. 2010, 90, 1238-1244. [CrossRef]

44. Banskota, A.H.; Sperker, S.; Stefanova, R.; McGinn, P.J.; O’Leary, S.J.B. Antioxidant properties and lipid composition of selected microalgae. J. Appl. Phycol. 2019, 31, 309-318. [CrossRef]

45. Vochita, G.; Oprica, L.; Gherghel, D.; Mihai, C.T.; Boukherroub, R.; Lobiuc, A. Graphene oxide effects in early ontogenetic stages of Triticum aestivum L. seedlings. Ecotoxicol. Environ. Saf. 2019, 181, 345-352. [CrossRef]

46. Ighodaroa, O.M.; Akinloie, O. First line defence antioxidants-superoxide dismutase (SOD), catalase (CAT) and glutathione peroxidase (GPX): Their fundamental role in the entire antioxidant defence grid, kinloye. Alex. J. Med. 2018, 54, 287-293. [CrossRef]

47. Chelikani, P.; Fita, I.; Loewen, P.C. Diversity of structures and properties among catalases. Cell. Mol. Life Sci. 2004, 61, 192-208. [CrossRef] [PubMed]

48. Hojati, M.; Moderres, S.A.M.; Karimi, M.; Ghanati, F. Responses of growth and antioxidant system in Carthamustinctorius L. under water deficit stress. Acta Physiol. Plant 2010, 33, 105-115. [CrossRef]

49. Hesham, A.; Eissa, A. Effect of chitosan coating on shelf life and quality of fresh-cut mushroom. J. Food Qual. 2007, 30, 623-645.

50. Grotto, D.; Santa Maria, L.; Valentini, J.; Paniz, C.; Schmitt, G.; Garcia, S.C.; Pomblum, V.J.; Rocha, J.B.T.; Farina, M. Importance of the lipid peroxidation biomarkers and methodological aspects for malondialdehyde quantification. Quím. Nova São Paulo 2009, 32, 169-174. [CrossRef]

51. Jain, M.; Mathur, G.; Koul, S.; Sarin, N.B. Ameliorative effects of proline on salt stress-induced lipid peroxidation in cell lines of groundnut (Arachis hypogea L.). Plant Cell. Rep. 2001, 20, 463-468. [CrossRef] 
52. Glaser, J.A. Biological degradation of polymers in the environment. In Plastics in the Environment; Gomiero, A., Ed.; Intechopen: London, UK, 2019; Chapter 5; p. 675. ISBN 978-1-78984-045-2.

53. Stloukal, P.; Verney, V.; Commereuc, S.; Rychly, J.; Matisova-Rychla, L.; Pis, V.; Koutny, M. Assessment of the interrelation between photooxidation and biodegradation of selected polyesters after artificial weathering. Chemosphere 2012, 88, 1214-1219. [CrossRef]

54. Gonçalves, C.M.B.; Coutinho, J.A.P.; Marrucho, I.M. Optical properties. In Poly(lactic acid): Synthesis, Structures, Properties, Processing, and Applications; Auras, R., Lim, L.-T., Selke, S.E.M., Tsuji, H., Eds.; John Wiley \& Sons: Hoboken, NJ, USA, 2010; pp. 97-111.

55. Stipanelov Vrandecic, N.; Erceg, M.; Jakic, M.; Klaric, I. Kinetic analysis of thermal degradation of poly (ethylene glycol) and poly (ethylene oxide)s of different molecular weight. Thermochim. Acta 2010, 498, 71-80. [CrossRef]

56. Darie-Nita, R.N.; Vasile, C.; Stoleru, E.; Pamfil, D.; Zaharescu, T.; Tartau, L.; Tudorachi, N.; Brebu, M.A.; Pricope, G.M.; Dumitriu, R.P.; et al. Evaluation of the rosemary extract effect on the properties of polylactic acid-based materials. Materials 2018, 11, 1825. [CrossRef]

57. Meaurio, E.; Lopez-Rodriguez, N.; Sarasua, J.R. Infrared spectrum of Poly (L-lactide): Application to crystallinity studies. Macromolecules 2006, 39, 9291-9301. [CrossRef]

58. Djonlagic, J.; Nikolic, M.S. Biodegradable polyesters: Synthesis and physical properties. In Handbook of Applied Biopolymer Technology: Synthesis, Degradation and Applications; Sharma, S.K., Mudhoop, A., Eds.; RSC: London, UK, 2011; Chapter 6; pp. 149-196.

59. Rouillon, C.; Bussiere, P.-O.; Desnoux, E.; Collin, S.; Vial, C.; Therias, S.; Gardette, J.-L. Is Carbonyl Index a quantitative probe to monitor polypropylene photodegradation? Polym. Degrad. Stab. 2016, 128, 200-208. [CrossRef]

60. Su, Z.; Li, Q.; Liu, Y.; Hu, G.-H.; Wu, C. Multiple melting behavior of Poly (lactic acid) filled with modified carbon black. J. Polym. Sci. Part B Polym. Phys. 2009, 47, 1971-1980. [CrossRef]

61. Ding, D.; Tao, Y.; Yan, L. Biodegradation of jute/poly (lactic acid) composites by fungi. Sci. China Tech. Sci. 2018, 61, 1705-1712. [CrossRef]

62. Musuc, A.M.; Badea-Doni, M.; Jecu, L.; Rusu, A.; Popa, V.T. FTIR, XRD, and DSC analysis of the rosemary extract effect on polyethylene structure and biodegradability. J. Therm. Anal. Calorim. 2013, 114, 169-177. [CrossRef]

63. Backes, E.H.; Pires, L.D.N.; Costa, L.C.; Passador, F.R.; Pessan, L.A. Analysis of the degradation during melt processing of PLA/Biosilicate ${ }^{\circledR}$ composites. J. Compos. Sci. 2019, 3, 52. [CrossRef]

64. Khana, S.; Nadir, S.; Shah, Z.U.; Shah, A.A.; Karunarathna, S.C.; Xu, J.; Khan, A.; Munir, S.; Hasan, F. Biodegradation of polyester polyurethane by Aspergillus tubingensis. Environ. Pollut. 2017, 225, 469-480. [CrossRef]

(C) 2020 by the authors. Licensee MDPI, Basel, Switzerland. This article is an open access article distributed under the terms and conditions of the Creative Commons Attribution (CC BY) license (http://creativecommons.org/licenses/by/4.0/). 